\title{
How to plan urban green space in cold regions of China to achieve the best cooling efficiency
}

\section{Bo Pang}

Chang'an University

Jingyuan Zhao ( $\boldsymbol{\nabla} 337410063 @ q q . c o m$ )

Chang'an University https://orcid.org/0000-0002-1278-5322

Jianxin Zhang

Chang'an University

Li Yang

Chang'an University

\section{Research Article}

Keywords: Urban heat island, Urban green space, Urban cold island, Threshold value of efficiency, Water/land ratio, Urban planning, Climate adaptation

Posted Date: March 30th, 2021

DOI: https://doi.org/10.21203/rs.3.rs-164277/v1

License: (1) (1) This work is licensed under a Creative Commons Attribution 4.0 International License. Read Full License

Version of Record: A version of this preprint was published at Urban Ecosystems on March 10th, 2022. See the published version at https://doi.org/10.1007/s11252-022-01202-1. 
How to plan urban green space in cold regions of China to achieve the best cooling efficiency

Bo Pang ${ }^{\text {a }}$, Jingyuan Zhao ${ }^{\text {a }}$, Jianxin Zhang ${ }^{\text {a }}$, Li Yang ${ }^{\text {a }}$

a Department of Architecture, Chang' an University, Xi'an 701165, China

* Corresponding author.

E-mail addresses: zjytougao@outlook.com 
Abstract: With the acceleration of urbanization, the urban heat island (UHI) effect has intensified. Urban green space can retard the UHI effectively. However, most existing work has only focused on hot regions, while little attention has been paid to cold regions. Furthermore, existing research does not classify urban green spaces according to the presence or absence of water, which will lead to inaccurate results. This paper takes four cities in cold regions of China as examples and studies the cooling effects of two different types of urban green space. The results indicate that for green spaces without water, the cooling intensity is related to the background temperature and area of the green spaces, while for green spaces containing water bodies, the area of the internal water body is the key influencing factor. Specifically, there is a threshold value of efficiency (TVoE) for the area of green spaces without water, while there is no TVoE for green spaces containing water bodies. Additionally, there is a TVoE for the water/land ratio of the green spaces containing water bodies in the four cities. The methods and results of this study can provide reference for future research and for urban planners designing urban green spaces.

Keywords: Urban heat island; Urban green space; Urban cold island; Threshold value of efficiency; Water/land ratio; Urban planning; Climate adaptation

\section{Introduction}

The Department of Economic and Social Affairs of the United Nations Secretariat (UN DESA) Population Division's "World Urbanization Prospects (2018 Revision)" [1] reported that more people live in urban areas than rural areas globally; specifically, the urban population accounted for $55 \%$ of the world population in 2018 . By $2050,68 \%$ of the global population is 
expected to live in urban areas. At present, the level of urbanization in Asia is close to $50 \%$, and this region has become the new focus of global urbanization. In China, the most populous country in the world, the urbanization rate reached $60.6 \%$ at the end of 2019 , and this rate is predicted to rise to $75 \%$ by $2030^{[2]}$ (2019 National Economic and Social Development Statistical Bulletin released by the Chinese National Bureau of Statistics).

Rapid urbanization has brought significant changes in land use, and with the loss of green spaces, coupled with the substantial increase in the amount of heat released artificially, the urban climate has deteriorated significantly and the urban environment has deteriorated seriously ${ }^{[3-6]}$. An important phenomenon is the generation of urban heat islands (UHIs). UHIs are urban areas that are warmer than surrounding non-urban areas ${ }^{[7-10]}$. Their presence can increase water consumption and energy use, aggravate environmental pollution, and cause harm to human health ${ }^{[11-16]}$. A considerable number of studies have demonstrated the significant cooling effect of urban green spaces, which can form urban cold islands (UCIs), improve people's outdoor thermal comfort, and significantly reduce the environmental pressure generated by urban heat islands ${ }^{[17-20]}$.

Many scholars have studied the cooling effect of urban green spaces. Studies have shown that the composition, configuration, size, shape, and coverage of green space patches are important factors determining their cooling effect ${ }^{[21-23]}$. There are large differences in the cooling effect of different configurations of green spaces. Trees can effectively block direct sunlight, and their cooling effect is significantly higher than that of surrounding herbs ${ }^{[24-25]}$. Some studies have shown that the shape index of green space plays an important role in its cooling effect. $\mathrm{Yu}$ et al. indicated that circular and square green spaces are significantly 
correlated with land surface temperature (LST) ${ }^{[26]}$. Liang et al. found that the area of green space is negatively correlated with the LST within a certain threshold: that is, within the certain threshold, the larger the green space area, the lower the LST ${ }^{[27]}$. Mikami and Sekita found that, if the green space area exceeds 20 ha, its cooling intensity will not increase with a further increase in area ${ }^{[28]}$. Moreover, Jaganmohan et al. concluded that increasing the spatial complexity of smaller green space has a negative effect on the cooling intensity but that increasing the spatial complexity of green space larger than 5.6 ha has a positive effect ${ }^{[29]}$.

Yu et al. ${ }^{[26] ~}{ }^{[30]}$ proposed the concept of the threshold value of efficiency (TVoE) to obtain the optimal scale of urban green space and optimize urban green space design. Le et al. ${ }^{[31]}$ found that the TVoE of green space in a tropical city (Hanoi) is 1 ha. Meanwhile, Yang et al. ${ }^{[32]}$ found that the TVoE of green space in a high-latitude city (Copenhagen) is 0.69 ha. Fan et al. ${ }^{[33]}$ investigated seven low-latitude Asian cities, and showed that the TVoE of the cities ranged from 0.6 to 0.95 ha. Yu et al. ${ }^{[30]}$ found that the TVoE in cities with a Temperate Monsoon climate and a Mediterranean climate is generally around 0.5 ha. Studies have shown that TVoE is highly correlated with urban background climate conditions ${ }^{[31-33]}$. Therefore, it is necessary to conduct research based on specific climate regions with different background climatic conditions. The cold region is one of the five climatic regions in China. It refers to the area where the average temperature of the coldest month is $(-10)-0{ }^{\circ} \mathrm{C}$ and the average number of days when the daily temperature is $\leqslant 5{ }^{\circ} \mathrm{C}$ is between 90 and 145 days. In summer, even in cities in cold regions, there are times when the temperature in the city is high. Therefore, it is necessary to pursue research on cold regions. However, existing research has mainly focused on cities in hot regions or individual cities in cold regions or has merely taken individual parks 
as examples. Meanwhile, the number of studies on specific climatic regions is relatively less, and there is a lack of comprehensive research and comparative analysis on cold regions. It also has the defects of a small number of samples and a single type of green space. Additionally, existing research shows that water bodies also have strong cooling effects ${ }^{[34-36]}$. Studies also found that the area and shape index of the water body are positively and negatively correlated with its cooling effect, respectively ${ }^{[37-39]}$. Broadly speaking, urban green spaces include urban blue-green spaces and urban green spaces. However, most existing studies have not separated urban blue-green spaces from urban green spaces. Due to the overlooked influence of water bodies, the research results will be inaccurate. Moreover, there are many uncertainties in existing research on green spaces containing water bodies, especially in terms of the threshold size and the optimal proportion of blue-green spaces ${ }^{[40]}$. Therefore, this article selected four cities in cold regions of China as case studies; sample green spaces were selected in each selected city according to whether they included water bodies. By analyzing and calculating the TVoE of the cooling effect of two different kinds of green space in each city, this study aimed to find the optimal green space areas in cold regions and to explore the relationship between the UCI effect of urban green space and landscape indicators and background temperature. We expect this work to provide a valuable reference for urban planners and managers seeking to mitigate the impact of UHIs.

\section{Methodology}

\subsection{Study area}

This study selected four cities in cold regions of China for analysis, namely Beijing, 
Tianjin, Xi'an, and Zhengzhou. The selected standards are as follows: (1) Although the selected city is in a cold area, there are requirements for heat protection in summer; (2) The selected city has a permanent population of more than 1 million; (3) The selected city has a high urbanization rate and a serious urban heat island effect; and (4) The selected city can represent the general geographic characteristics of China's cold regions in terms of temperature, population density, and urban structure. The populations and geographic details of these cities are shown in Table 1.

\begin{tabular}{|c|c|c|c|c|c|c|c|}
\hline City & $\begin{array}{l}\text { Area } \\
\left(\mathrm{km}^{2}\right)\end{array}$ & $\begin{array}{l}\text { Study area } \\
\qquad\left(\mathrm{km}^{2}\right)\end{array}$ & $\begin{array}{l}\text { Resident } \\
\text { population } \\
\text { (million) }\end{array}$ & $\begin{array}{l}\text { Urbanization } \\
\text { rate }\end{array}$ & Location & Climate & $\begin{array}{l}\text { Average temperature } \\
\text { in summer (From } \\
\text { June to August) } \\
\left({ }^{\circ} \mathrm{C}\right)\end{array}$ \\
\hline Beijing & $16,410.54$ & 1378.04 & 21.53 & $86.50 \%$ & $\begin{array}{c}39^{\circ} 56^{\prime} \mathrm{N} \\
116^{\circ} 20^{\prime} \\
\mathrm{E}\end{array}$ & Temperate monsoon & 31 \\
\hline Tianjin & $11,966.45$ & 176.7 & 15.62 & $83.15 \%$ & $\begin{array}{l}39^{\circ} 13^{\prime} \mathrm{N} \\
117^{\circ} 2^{\prime} \mathrm{E}\end{array}$ & Temperate monsoon & 32 \\
\hline Xi'an & 10,752 & 977.44 & 10.20 & $74.01 \%$ & $\begin{array}{c}34^{\circ} 15^{\prime} \mathrm{N} \\
108^{\circ} 55^{\prime} \\
\mathrm{E}\end{array}$ & Temperate monsoon & 32 \\
\hline
\end{tabular}




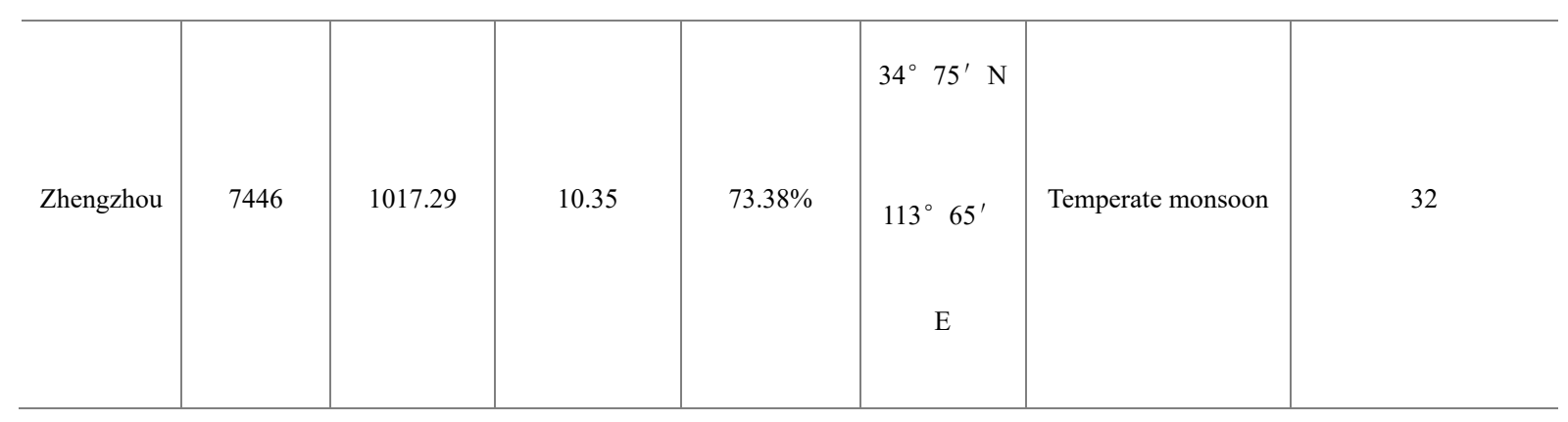

Table 1

Overview of selected cities

Source: CHINA CITY STATISTICAL YEARBOOK (2019)

Note: The study area is the main urban area of each city.

\subsection{Data collection and processing}

\subsubsection{Land surface temperature (LST) retrieval}

Previous studies showed that reliable and accurate LST can be obtained by using the Radiative Transfer Equation (RTE) algorithm ${ }^{[16][22]}$. Therefore, the RTE algorithm proposed by Jiménez-Muñoz et al. ${ }^{[23]}$ was chosen to calculate LST in this study.

The principle of the RTE involves estimating the impact of the atmosphere on the surface thermal radiation and then subtracting this part of the atmospheric impact from the total amount of thermal radiation observed by the satellite sensor to obtain the surface thermal radiation intensity. After that, LST can be obtained by converting this thermal radiation intensity. The RTE is calculated as follows:

$$
L_{\lambda}=\left[\varepsilon B\left(T_{S}\right)+(1-\varepsilon) L_{\mathrm{atm}, \mathrm{i}} \downarrow\right] \tau+L_{\mathrm{atm}, \mathrm{i}} \uparrow,
$$

where $L_{\lambda}$ is a radiance pixel value received by a satellite sensor, $\varepsilon$ is the surface emissivity, 
$T_{S}$ is the LST, $B\left(T_{S}\right)$ is the ground radiance, and $\tau$ is the atmospheric transmittance. The atmospheric transmittance, the atmospheric downward radiance $L_{\text {atm, i }} \downarrow$, and the upward radiance $L_{\text {atm, i }} \uparrow$ can be estimated (http://atmcorr.gsfc.nasa.gov/). Therefore, $B\left(T_{S}\right)$ can be calculated by Eq. (2), and then the LST can be determined by Eq. (3):

$$
\begin{aligned}
& B\left(T_{S}\right)=\left[L_{\lambda}-L_{\mathrm{atm}, \mathrm{i}} \uparrow-\tau(1-\varepsilon) L_{\mathrm{atm}, \mathrm{i}} \downarrow\right] \tau \varepsilon \\
& \left.T_{S}=K_{2} / \ln \left(K_{1} / B\left(T_{S}\right)+1\right)\right),
\end{aligned}
$$

where $K_{1}=774.89 \mathrm{~W} /(\mathrm{m} 2 * \mu \mathrm{m} * \mathrm{sr})$ and $K_{2}=1321.08 \mathrm{~K}$ in Landsat images. Landsat 8 images collected in summer 2019 were used as input data for the LST inversion (Table 2). Figure 1 shows the results of the LST.

\begin{tabular}{c|c|c}
\hline City & Landsat Scene ID & Acquisition date and time (GMT) \\
\hline Beijing & LC81230322019229LGN00 & 03 Aug 2019; 02:42:10 \\
\hline Tianjin & LC81230332019229LGN00 & 19 Jul 2019; 03:30:28 \\
\hline Xi'an & LC81270362019225LGN00 & 21 Aug 2019; 02:18:29 \\
\hline Zhengzhou & LC81240362019188LGN00 & 03 Aug 2019; 03:45:01 \\
\hline
\end{tabular}

Table 2

The information of Landsat 8 images

\subsubsection{Land cover classification}

In this study, the ENVI software (Exelis Visual Information Solutions, USA) was used to 
classify the land cover of the four studied cities with a supervised classification method. The data source is the atmospherically corrected Landsat 8 images of each city from summer 2019 (Table 2). The Landsat 8 satellite was launched by the National Aeronautics and Space Administration (NASA) on 11 February 2013. The satellite carries two main payloads-the Operational Land Imager (OLI) and the Thermal Infrared Sensor (TIRS) — which are currently used in various fields such as land planning, regional planning, land use, forest monitoring, and agricultural yield estimation.

Visual interpretation methods were used to select training samples for five types of land cover, namely green space, cultivated land, construction land, water, and unused land. Green space refers to land covered by vegetation, which is mainly a mixture of grass, shrubs, and trees; cultivated land refers to land on which crops are grown; construction land refers to buildings and impervious land; water refers to rivers, lakes, and ponds; and unused land refers to land other than agricultural and construction land. The accuracy of the land cover classification results of the four cities were $83.6 \%, 86.9 \%, 85.2 \%$ and $88.8 \%$ respectively. 


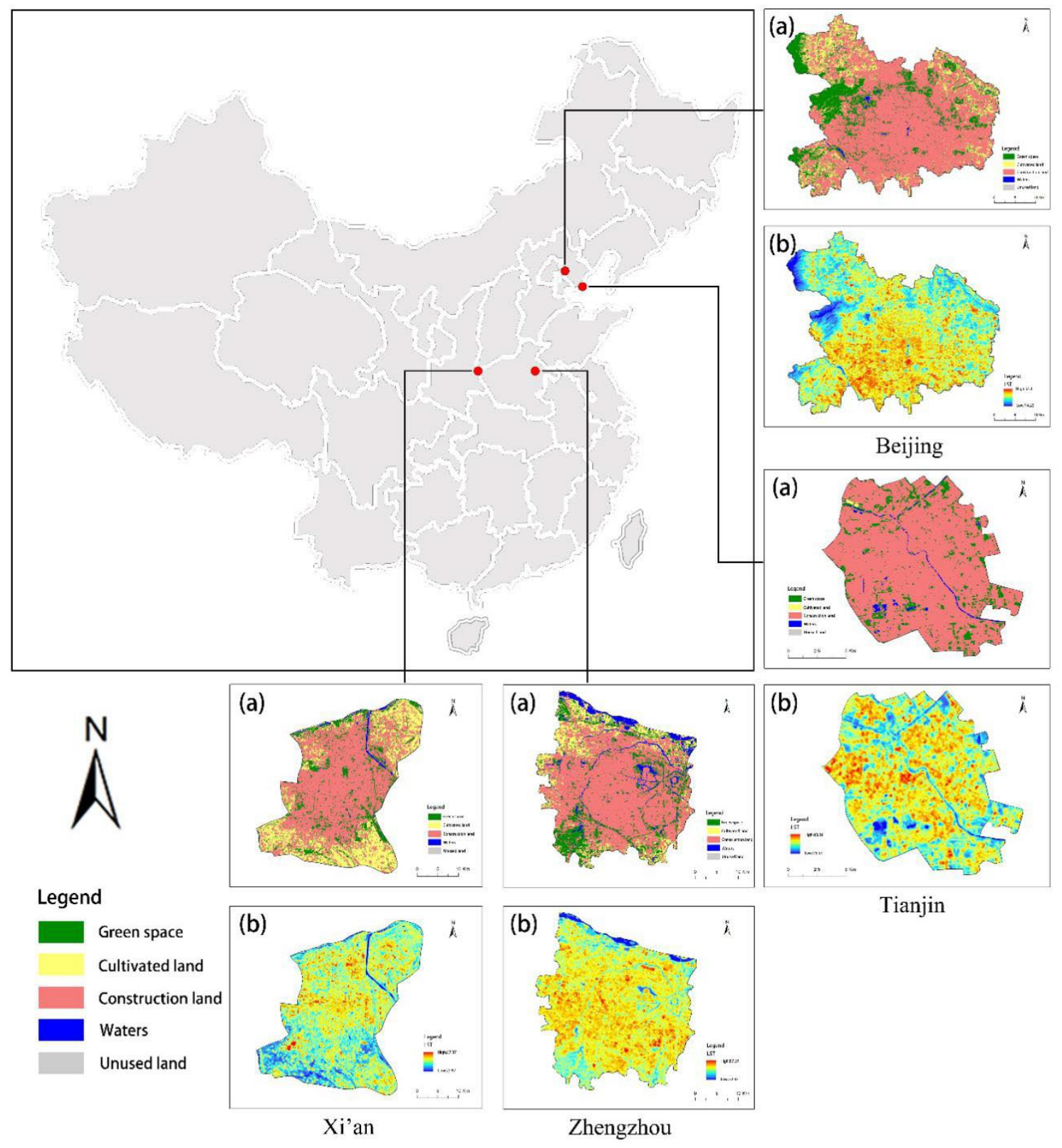

Fig 1. The basic geographic information of the selected cities: (a) Land cover classification; (b) Land surface temperature.

\subsubsection{Sample green space extraction}

In previous studies on the cooling effect of urban green space, there were problems such as a small number of samples, only considering a single type of green space, and ignoring interference from other cooling factors. Due to the limited accuracy of land cover classification 
results, this study uses high-resolution Google Earth satellite images to select sample green spaces for each city based on the results of land cover classification. The selection principles are as follows: (1) The area of the green space is different; (2) The urban green space is classified and selected according to the presence or absence of internal water bodies; (3) There must be a certain distance between the sample green spaces to prevent mutual interference due to proximity; and (4) It was attempted to avoid large external areas of water within $100 \mathrm{~m}$ of the green space, which could cause inaccurate data due to the influence of the external water ${ }^{[33]}$. According to this principle, based on the results of the land cover classification, and supplemented by high-resolution Google Earth images, the boundary of the sample green space vector was drawn in the ArcGIS software (Esri, Redlands, CA, USA). After screening, in each city, 30 green spaces without internal water bodies and 20 green spaces with internal water bodies were selected. The specific locations of the green spaces selected in each city are shown in Figure 2. 

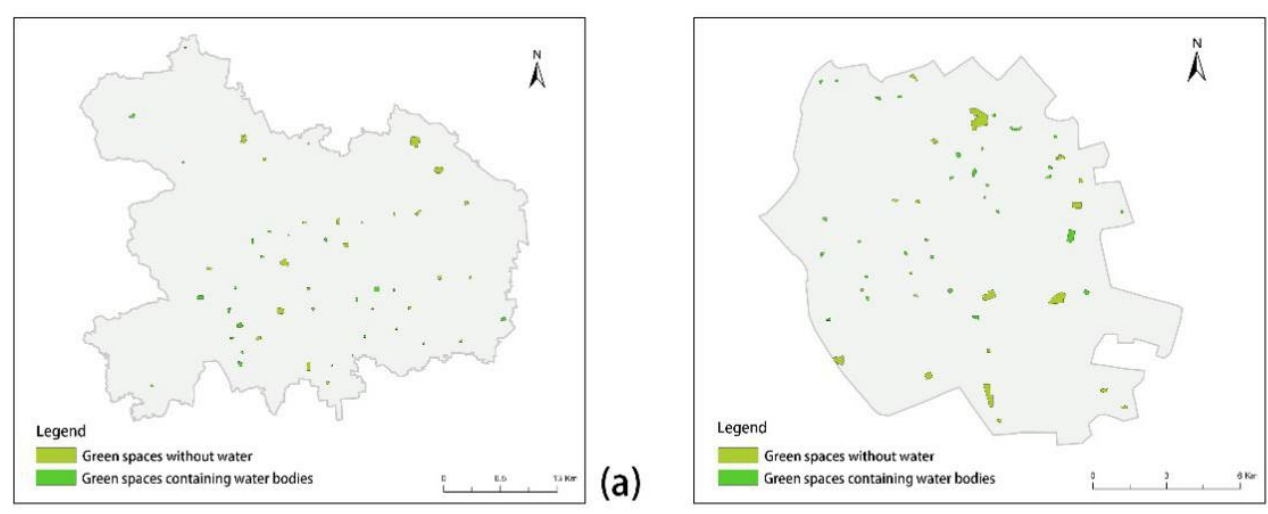

(b)
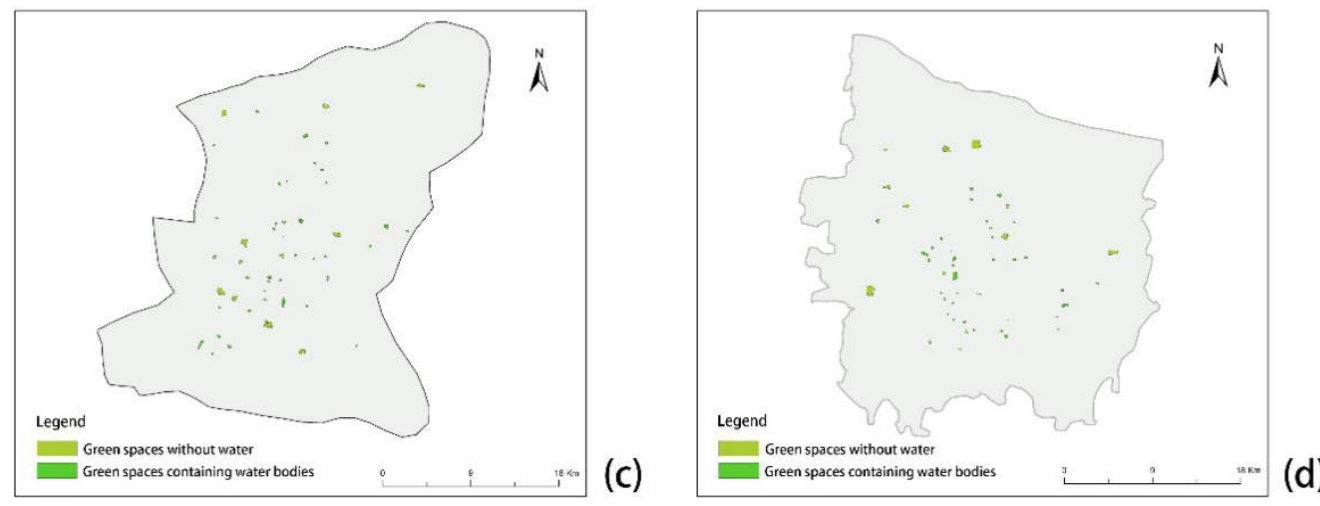

Fig 2. Results of urban green space selection: (a) Beijing; (b) Tianjin; (c) Xi’an; (d) Zhengzhou.

\subsection{UCI effect analysis}

In this study, as in the work by Yu, the UCI effect was defined as the difference in LST between a green space and its surrounding urban areas. Two indicators were selected to characterize the UCI effect of green space: the UCI intensity and the UCI extent. UCI intensity refers to the LST difference between the green space and the turning point of the first LST drop outside the patch. The UCI extent is the distance from the edge of the green space to the first turning point of cooling.

In order to calculate the UCI effect of each green space, we first calculated the average LST inside each selected green patch and then created different numbers of $30 \mathrm{~m}$ buffer zones for different types of green patch. Finally, the UCI intensity and extent of each green space 
were obtained, and correlation analyses of the obtained results were carried out with the Microsoft Excel software.

\subsection{Calculation of TVoE}

Yu et al. ${ }^{[26]}$ proposed the use of a TVoE to estimate the optimal green patch area. According to the "law of diminishing marginal utility," before TVoE is reached, as the area of green patches increased, the UCI effect of green patches also increased significantly. However, after the green patch area reaches or exceeds the $\mathrm{TVoE}$, continuing to increase the patch area will produce a relatively insignificant increase in UCI intensity. Therefore, we believe that it is cost-effective to expand the patch area until the TVoE is reached. This paper used the Excel software to conduct logarithmic regression analysis of the area of green patches and UCI intensity. The TVoE occurs where the slope of the obtained logarithmic function is 1 .

\subsection{Selection of landscape indicators}

Previous studies have shown that the UCI effect of green space is correlated with various landscape indices, and the main influencing factors are the size, shape, complexity, and climate background of the green space ${ }^{[41-44]}$. The present study started from the patch scale and landscape scale, selected the following indices, performed linear regression analysis, and explored the relationship between the indices and the UCI effect of green space: (1) Background temperature (BGT): Average temperature inside each green patch; (2) Patch area (Area): The area of each green patch; (3) Landscape Shape Index (LSI): Describes the shape complexity of the green space. The calculation formula of the LSI is as follows: 


$$
L S I=\frac{0.25 E}{\sqrt{A}} \text {, }
$$

where $\mathrm{E}$ indicates the perimeter of the patch and $\mathrm{A}$ is the area of the patch. The larger the LSI value, the more complex the shape of the patch. LSI $\geqslant 1$, with no upper limit.

\section{Results}

\subsection{The influence of landscape indices on UCI intensity and UCI extent}

\subsubsection{Basic information}

The basic information of each city is shown in Table 3. The data was obtained by analyzing the Landsat 8 images shown in Table 2. For example, in Zhengzhou and Xi'an, the background temperature reached $38.23{ }^{\circ} \mathrm{C}$ and $37.38{ }^{\circ} \mathrm{C}$. The recommended WBGT threshold according to ISO 7243 is $32-33{ }^{\circ} \mathrm{C}$ if it is considered that people wear summer clothes $(0.5$ clo $)$ in summer for safety during outdoor leisure. When the WBGT value of the environment exceeds this value for a long time, safety protection measures should be taken to prevent the human body from suffering thermal damage. This shows there are times when the temperature in the cities in cold regions in summer is higher than the WBGT value. So it is necessary to prevent heat in summer in cities in cold regions. As can be seen from Table 3, urban green space has a strong cooling effect. Among the four cities, the average cooling effect of urban green space was the highest in Beijing, reaching $3.84{ }^{\circ} \mathrm{C}$, and the lowest in Zhengzhou, reaching $1.81{ }^{\circ} \mathrm{C}$. Different types of urban green space have different degrees of cooling. The average cooling intensity of green spaces without water is between 1.36 and $1.80{ }^{\circ} \mathrm{C}$. The green spaces containing water bodies have a stronger cooling effect than the green spaces without water, 
with an average cooling intensity of $2.50-2.86{ }^{\circ} \mathrm{C}$. The difference between the cooling effects of the two different types of green space in Beijing, Tianjin, Xi'an, and Zhengzhou is 0.74 , $0.99,1.28$, and $1.12{ }^{\circ} \mathrm{C}$, respectively. The average cooling extent of green spaces with water is between 420 and $583.5 \mathrm{~m}$, which is much higher than that of green spaces without water (from 174 to $219 \mathrm{~m}$ ). Beijing and Xi'an have high values of NDVI (Normalized Difference Vegetation Index) and Tianjin has high urban relative humidity.

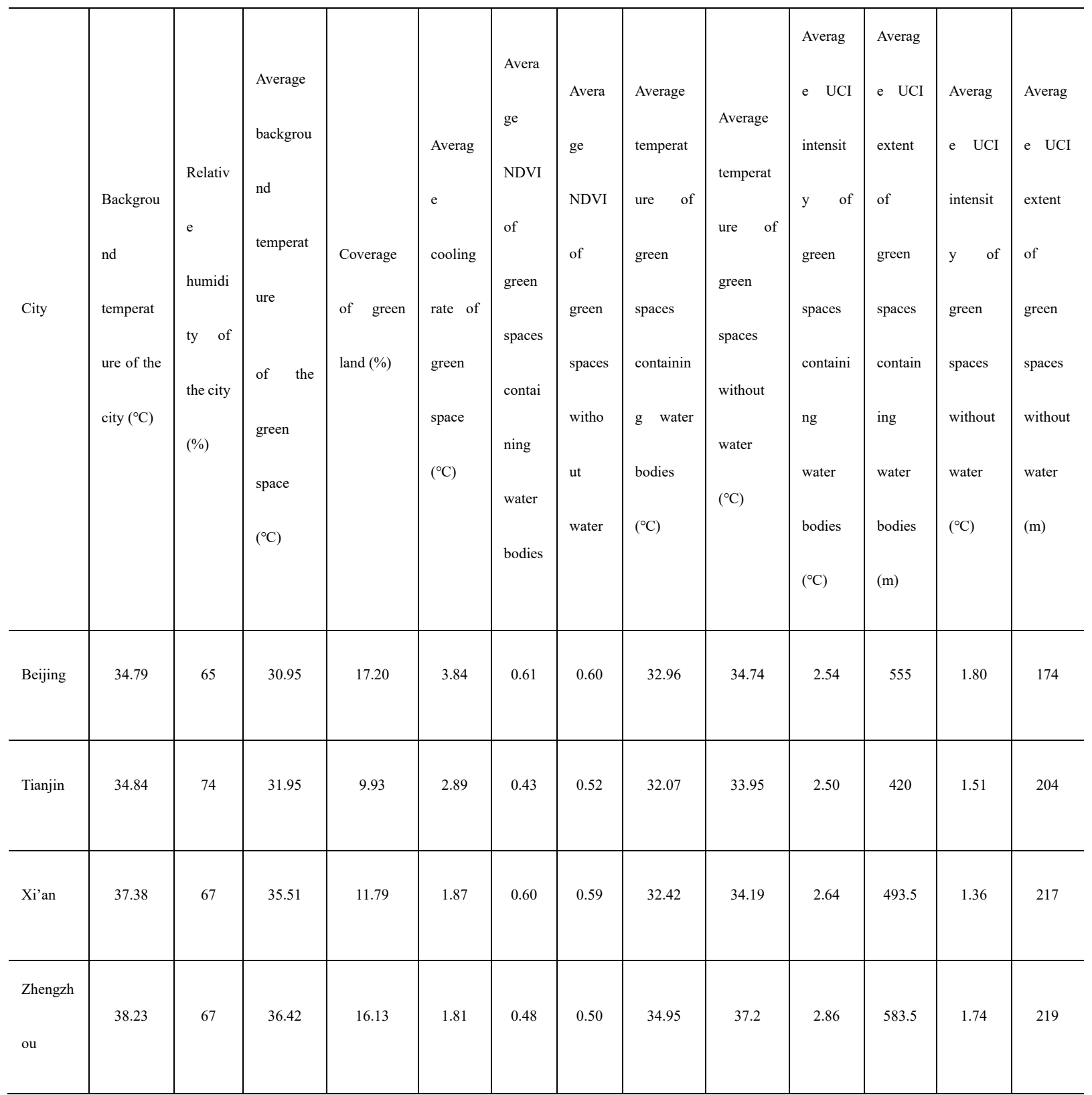

Table 3 
Basic information of selected cities

\subsubsection{The influence of background temperature (BGT) on UCI intensity and UCI extent}

Figure 3 shows the results of the linear regression analysis of the background temperature and UCI intensity and UCI extent of two different types of urban green space in each city. For green spaces without water, the BGT of the green space is negatively correlated with the UCI intensity - that is, the higher the average temperature inside the green space, the worse the cooling effect of the green space. Beijing, Tianjin, and Zhengzhou have strong correlations between the BGT and the UCI intensity, with $\mathrm{R}^{2}$ values of $0.32,0.32$, and 0.43 , respectively, while Xi'an has a weak correlation, with an $\mathrm{R}^{2}$ of 0.17 . For green spaces containing water bodies, there is no correlation between the BGT of green space and UCI intensity. In Beijing and Xi'an, the correlation between the BGT of the green space and the UCI intensity is extremely low, with $\mathrm{R}^{2}$ values of 0.04 and 0.004 , respectively, while Tianjin and Zhengzhou have strong negative correlations, with $\mathrm{R}^{2}$ values of 0.51 and 0.37 , respectively.

In cold regions, there is no correlation between the BGT of the green space and the cooling extent. For green spaces without water, Tianjin and Zhengzhou have strong correlations, with $\mathrm{R}^{2}$ values of 0.37 and 0.27 , respectively, while $\mathrm{Xi}$ ' an has a weak correlation, with an $\mathrm{R}^{2}$ value of only 0.17 . There is almost no correlation between the BGT and the UCI extent in Beijing. For green spaces containing water bodies, Beijing and Zhengzhou are highly correlated, with $\mathrm{R}^{2}$ values of 0.28 and 0.38 , respectively, while Tianjin and $\mathrm{Xi}^{\prime}$ an have almost no correlation. 

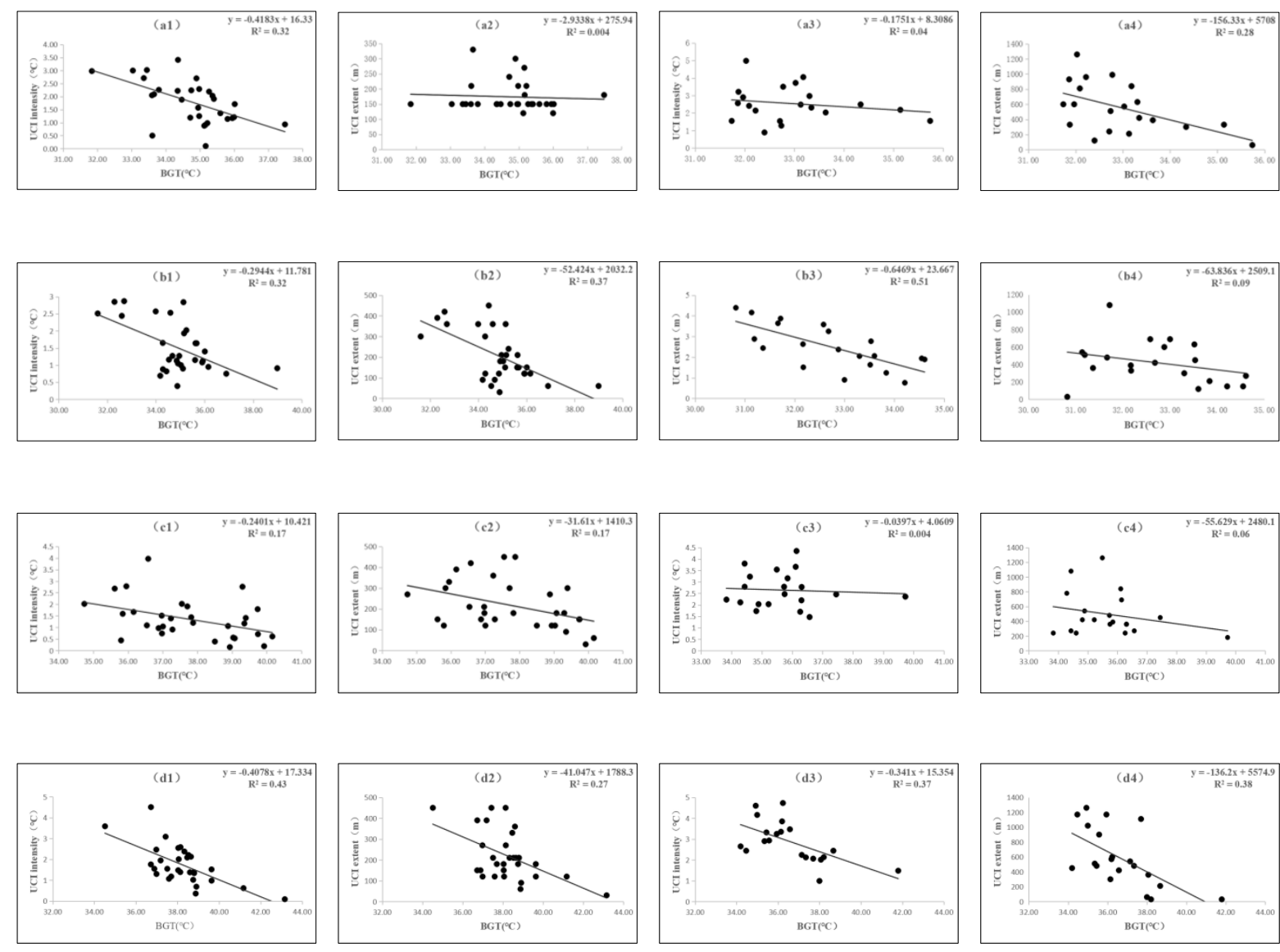

Figure 3. Correlation analysis between background temperature and UCI intensity and UCI

range for two different types of urban green space in each city: $($ a1 $),($ a2 $):$ green spaces without water in Beijing;（a3），(a4）: green spaces containing water bodies in Beijing;（b1），(b2）: green spaces without water in Tianjin;（b3），(b4）: green spaces containing water bodies in Tianjin;（c1），(c2）: green spaces without water in Xi'an;（c3），(c4）: green spaces containing water bodies in Xi'an;（d1），(d2）: green spaces without water in Zhengzhou;（d3），(d4）: green spaces containing water bodies in Zhengzhou.

\subsubsection{The influence of Patch Area on UCI intensity and UCI extent}

Figure 4 shows the results of the linear regression analysis of the patch area and UCI intensity and UCI extent for different types of green space in each city. As shown, the area of 
green spaces without water in each city is positively correlated with UCI intensity to varying degrees - that is, as the area of green space increases, the UCI intensity also increases $\left(\mathrm{R}^{2}=0.24\right.$, $0.20,0.32$, and 0.28 for Beijing, Tianjin, $\mathrm{Xi}$ 'an, and Zhengzhou, respectively). There is no correlation between the area of green spaces with water and the UCI intensity in any city.

There is no correlation between the area of green space in each city and the UCI extent. Except for Beijing, the area of green spaces without water is positively correlated with the scope of UCI in each city $\left(\mathrm{R}^{2}=0.14,0.18\right.$, and 0.22 in Tianjin, Xi'an, and Zhengzhou, respectively). The correlations between the area of green spaces with water and the UCI extent are extremely low in Beijing and Tianjin, while those in Xi'an and Zhengzhou are positive $\left(\mathrm{R}^{2}=0.25\right.$ and 0.20 , respectively).
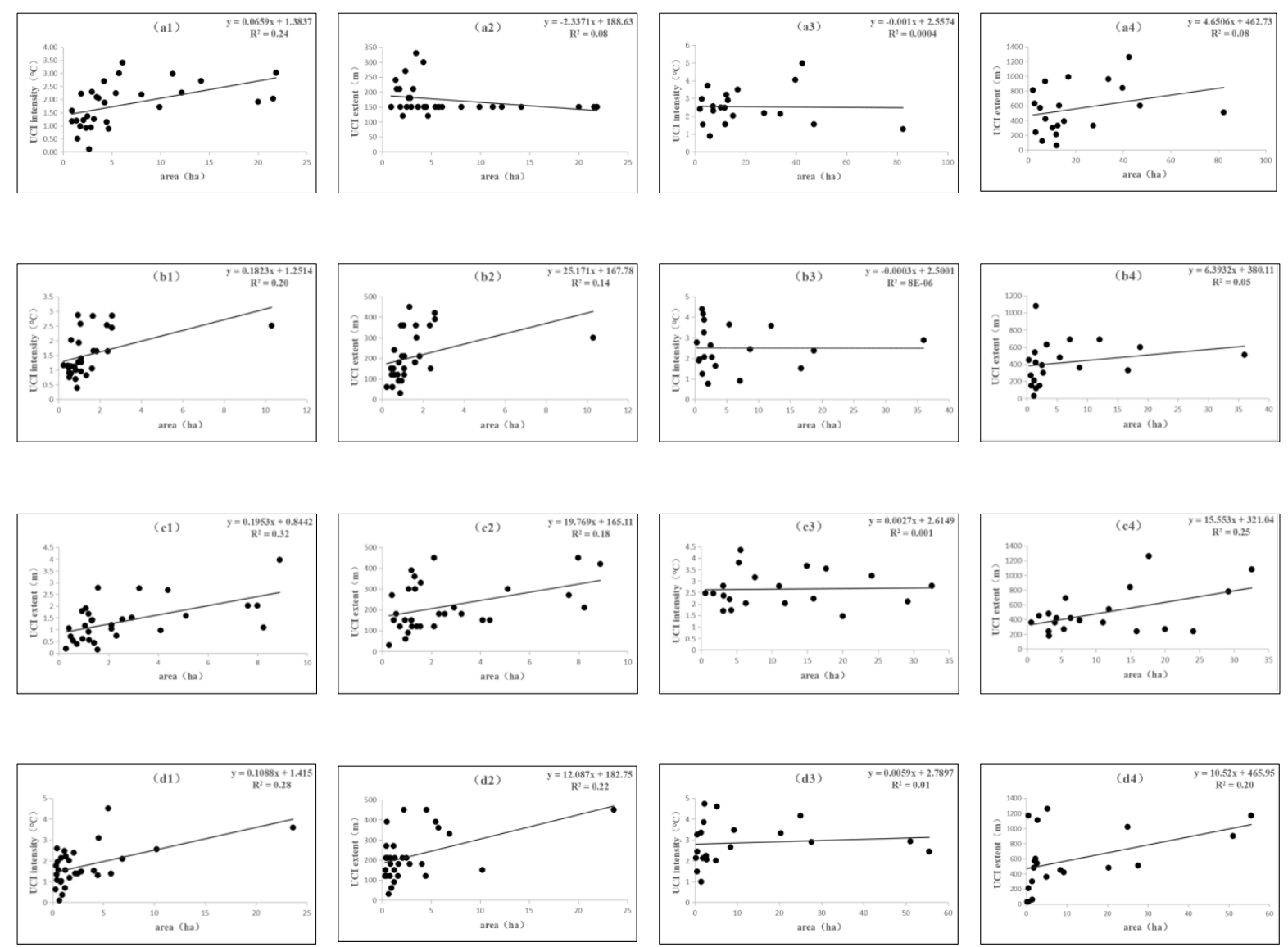
Figure 4 Correlation analysis between the area of two different types of urban green space in each city with UCI intensity and UCI extent:（a1），(a2）: green spaces without water in Beijing; （a3），(a4）: green spaces containing water bodies in Beijing;（b1），(b2）: green spaces without water in Tianjin;（b3），(b4）: green spaces containing water bodies in Tianjin;（c1）, （c2）: green spaces without water in Xi'an;（c3），(c4）: green spaces containing water bodies in Xi'an;（d1），(d2）: green spaces without water in Zhengzhou;（c3），(c4）: green spaces containing water bodies in Zhengzhou.

\subsubsection{The relationship between LSI and UCI intensity and UCI extent}

In this study, the LSI was selected to research the relationship between the shape of green space and UCI intensity and UCI extent. The average LSIs of the two different types of green space in the four cities are shown in Table 4. The results for the linear regression of the LSI for each type of green space and UCI intensity and UCI extent are shown in Figure 5. It can be seen from Table 3 that the average LSIs of the two different types of green space in the four cities are not high, indicating that the shape complexity of the selected green space patches is low and that the shape is basically close to a square.

\begin{tabular}{c|c|c|c|c}
\hline City & Beijing & Tianjin & Xi'an & Zhengzhou \\
\hline Average LSI of green & 1.11 & 1.35 & 1.25 & 1.18 \\
spaces without water & 1.12 & 1.29 & 1.17 & \\
\hline Average LSI of green & & & & 1.16 \\
spaces containing water & & & & \\
\hline
\end{tabular}

Table 4 
Average LSIs of the two different types of green space in the four cities.
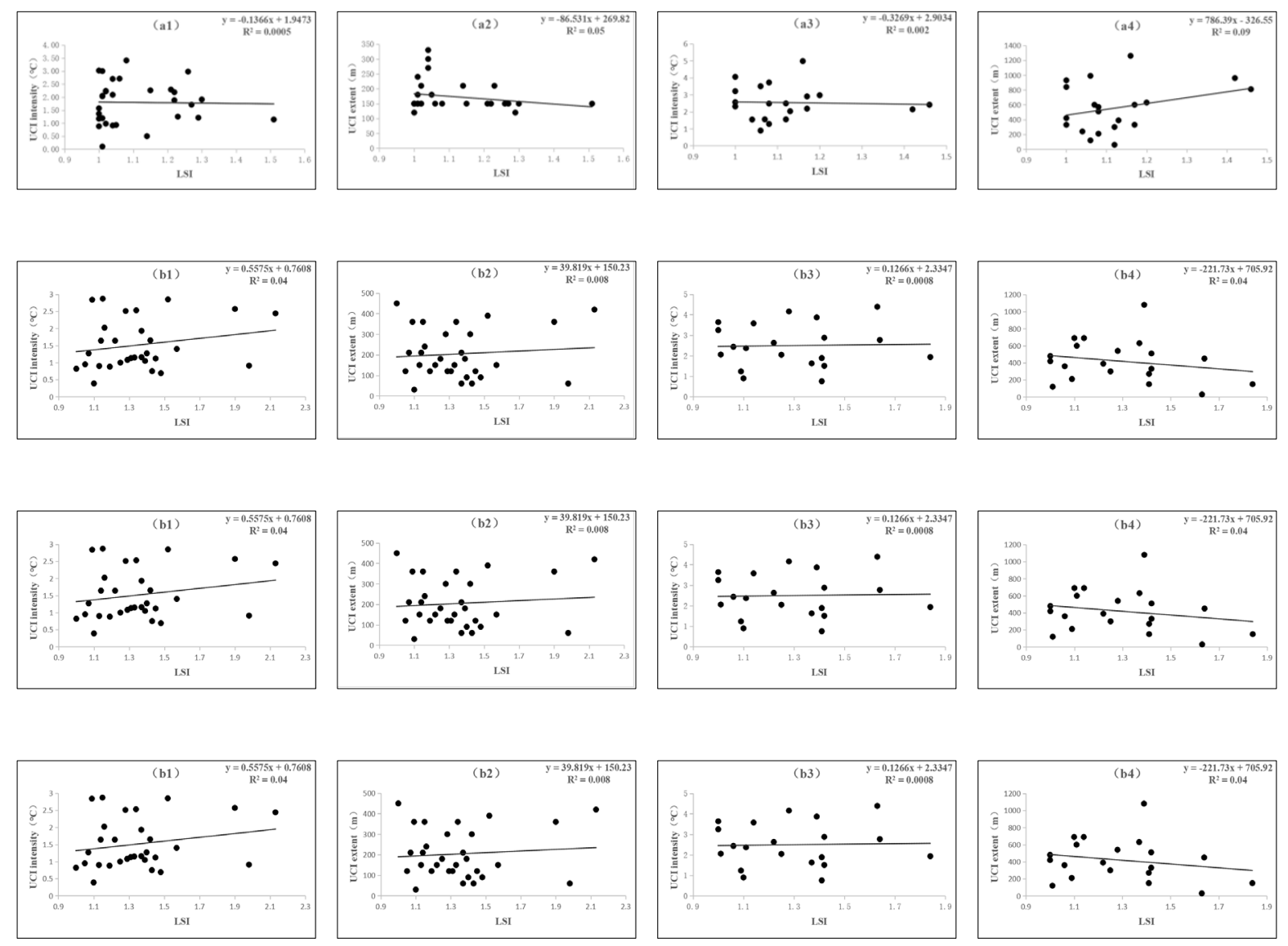

Figure 5. Correlation analysis between the landscape sub-dimension index, UCI intensity, and

UCI extent of two different types of urban green space in each city:（a1），(a2）: green spaces without water in Beijing;（a3），(a4）: green spaces containing water bodies in Beijing;（b1）, （b2）: green spaces without water in Tianjin;（b3），(b4）: green spaces containing water bodies in Tianjin;（c1），(c2）: green spaces without water in Xi’an;（c3），(c4）: green spaces containing water bodies in Xi'an;（d1），(d2）: green spaces without water in Zhengzhou;（c3）, (c4) : green spaces containing water bodies in Zhengzhou.

It can be seen from Figure 5 that there are no correlations between the LSI of the two different types 
of urban green space, UCI intensity, and UCI extent in any city.

\subsection{Analysis of TVoE}

Figure 6 shows the results of the logarithmic regression analysis between the UCI intensity and the area of the two different types of green space in the four cities. It can be seen that the TVoEs of green spaces without water in Beijing, Tianjin, Xi'an, and Zhengzhou are 0.53 ha, 0.57 ha, 0.55 ha, and 0.44 ha, respectively. Therefore, for cities in cold regions of China, the optimal patch area of green spaces without water is between 0.44 ha and 0.57 ha. The logarithmic regression result $\left(\mathrm{R}^{2}\right)$ for the UCI intensity of the green spaces with water in the four cities is close to 0 , so it is considered that there is no TVoE.

Water has a high heat capacity and low thermal conductivity. The evaporation of water is the main cooling mechanism for water bodies. These characteristics of water lead to a significant reduction in sensible heat transfer capacity, which leads to a change in the heat transfer mode, the so-called "constant temperature effect". The constant temperature effect helps to form a more stable climate, including lowering the maximum temperature and increasing the minimum temperature ${ }^{[45]}$. Therefore, we believe that for green spaces containing water bodies, due to the influence of internal water bodies, there may not be a universal optimal green space patch area; however, we can further explore the relationship between the internal water-body area of green space and UCI intensity. 

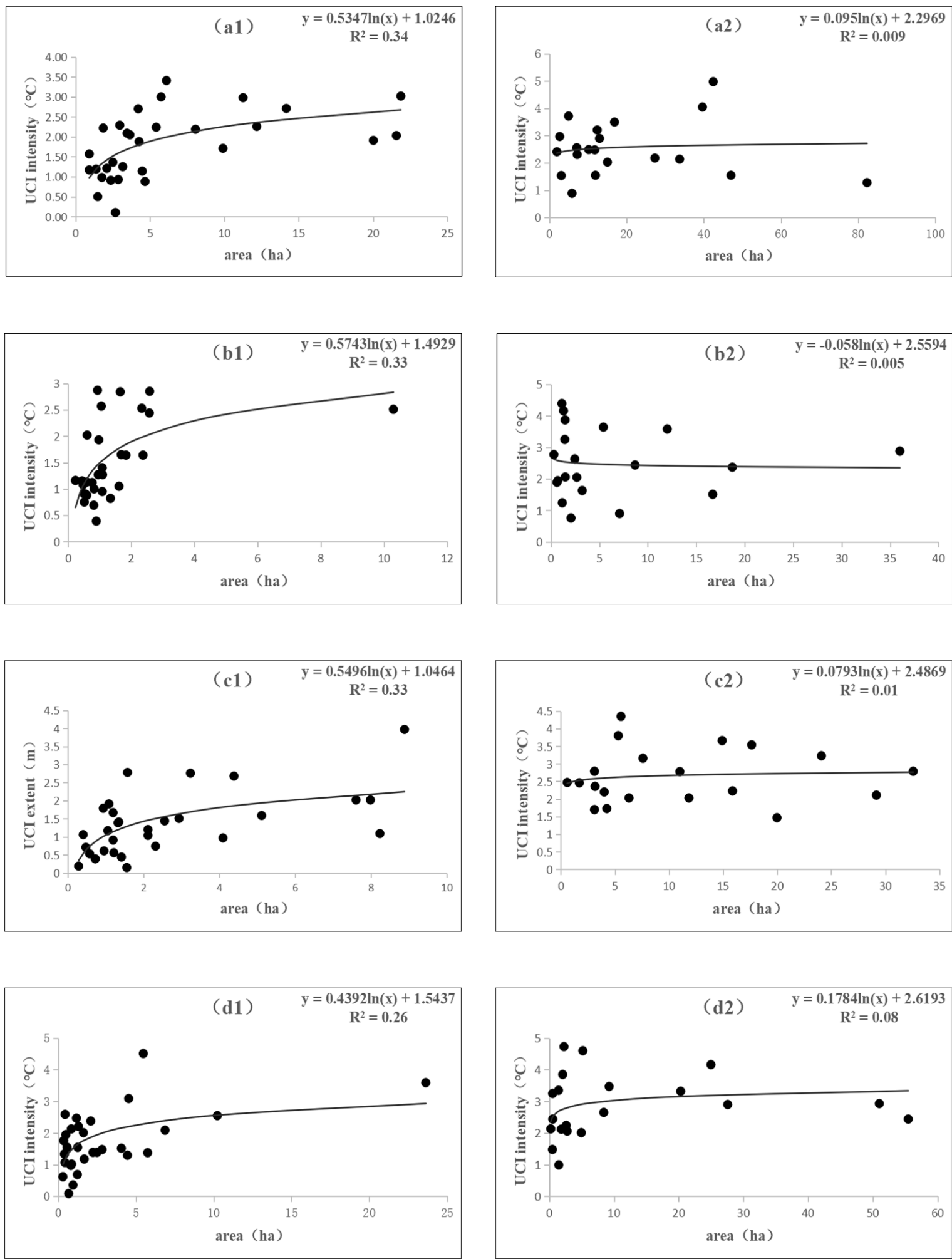

Figure 6. TVoEs of two different types of urban green space in each city: (a1): green spaces without water in Beijing; (a2): green spaces containing water bodies in Beijing; (b1): green spaces without water in Tianjin; (b2): green spaces containing water bodies in Tianjin; (c1): green spaces 
without water in Xi'an; (c2): green spaces containing water bodies in Xi'an; (d1): green spaces without water in Zhengzhou; (d2): green spaces containing water bodies in Zhengzhou.

3.3 Correlation analysis and TVoE of water area inside green space, UCI intensity, and BGT of green spaces

3.3.1 Correlation analysis of water area inside green space, BGT, and UCI intensity of green spaces
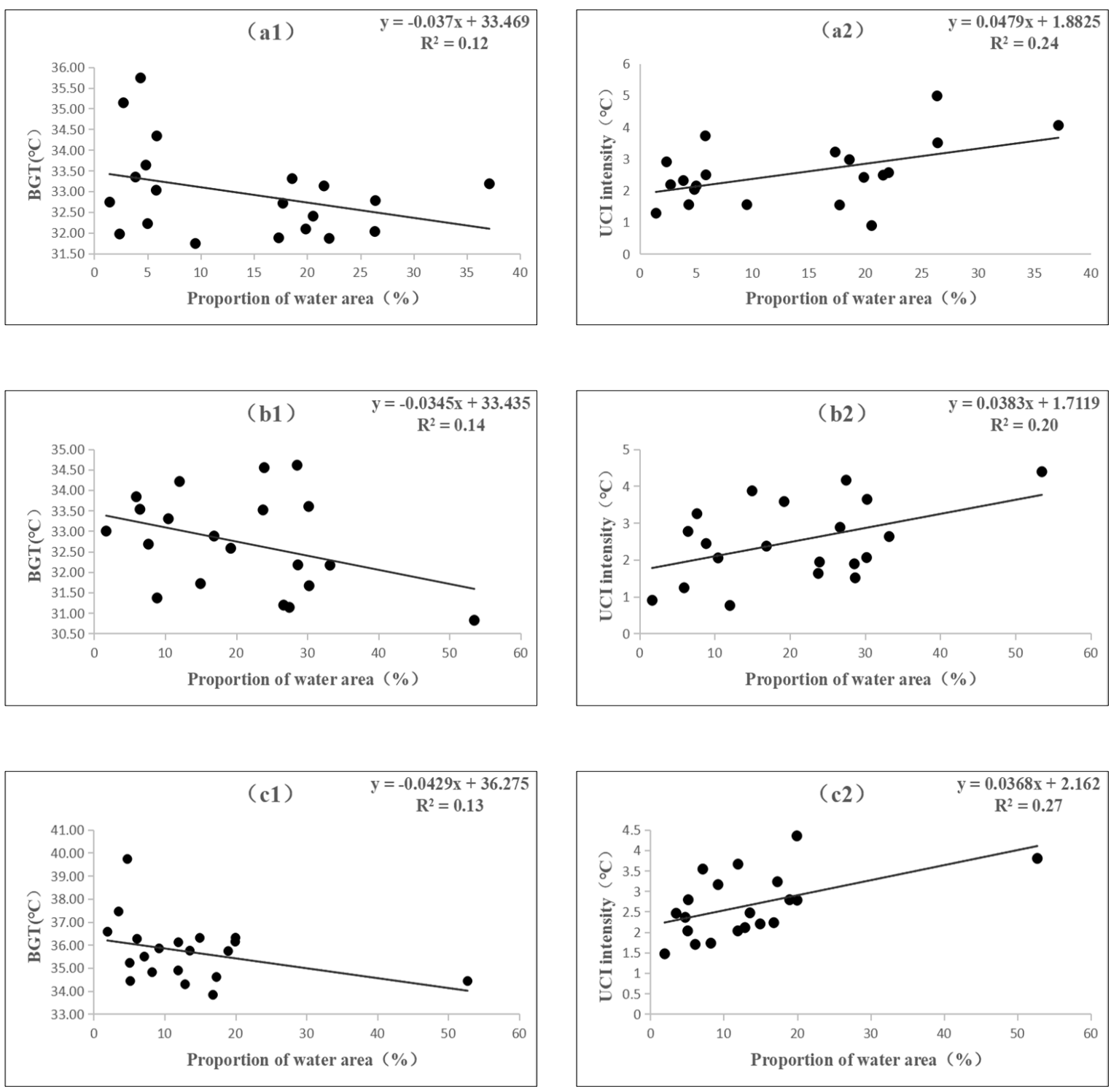

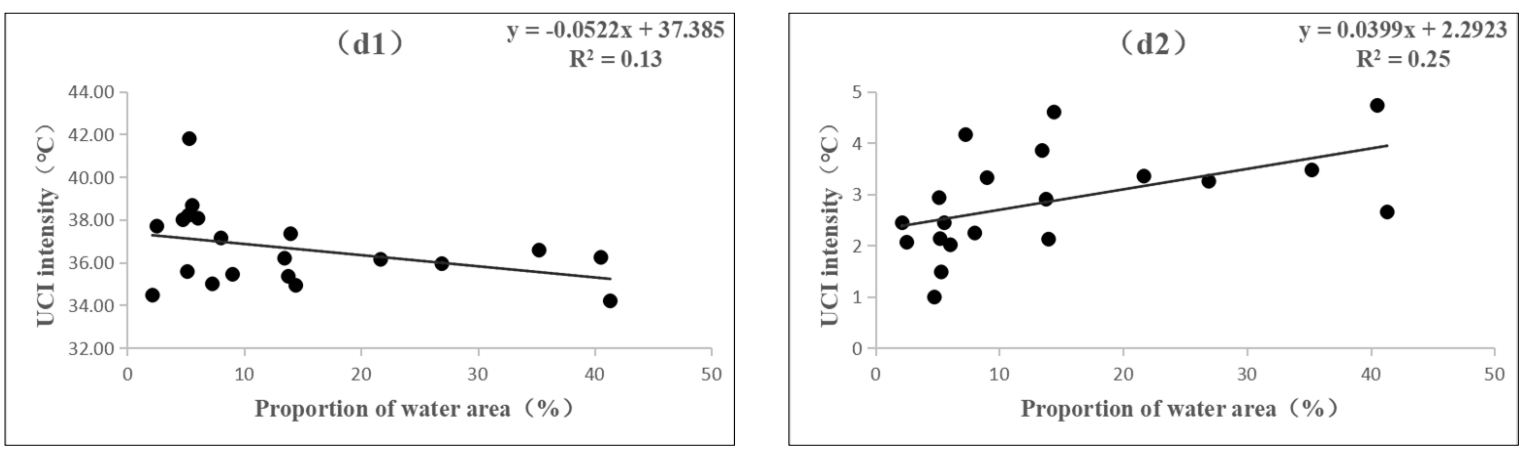

Figure 7. Correlation analysis of the proportion of water body area and UCI intensity and the internal temperature of green spaces with water in each city: (a) Beijing; (b) Tianjin; (c) Xi'an; (d)

\section{Zhengzhou.}

It can be seen from Figure 7 that the proportions of the water areas in green space in the four cities have weak negative correlations with the $\mathrm{BGT}\left(\mathrm{R}^{2}=0.12,0.14,0.13\right.$, and 0.13 , respectively). That is, as the proportion of water area increases, the BGT of the green space gradually decreases. The proportions of water area are positively correlated with the UCI intensities of green spaces $\left(\mathrm{R}^{2}=0.24,0.20,0.27\right.$, and 0.25 for Beijing, Tianjin, Xi'an, and Zhengzhou, respectively); that is, the larger the proportion of water in the green space, the stronger the cooling effect of the green space.

\subsubsection{TVoE of the water/land ratio}

In order to quantify the cooling effect of urban green spaces containing water bodies, this paper proposes a new quantitative water/land ratio. The water/land ratio refers to the ratio of the water area to the green area (including the green area and the area for a small number of buildings and road paving) in a single urban green patch. The calculation results of the $\mathrm{TVoE}$ of the water/land ratio of the green spaces containing water bodies are shown in Figure 
8, which are $0.42,0.52,0.50$, and 0.55 for Beijing, Tianjin, Xi'an, and Zhengzhou, respectively.
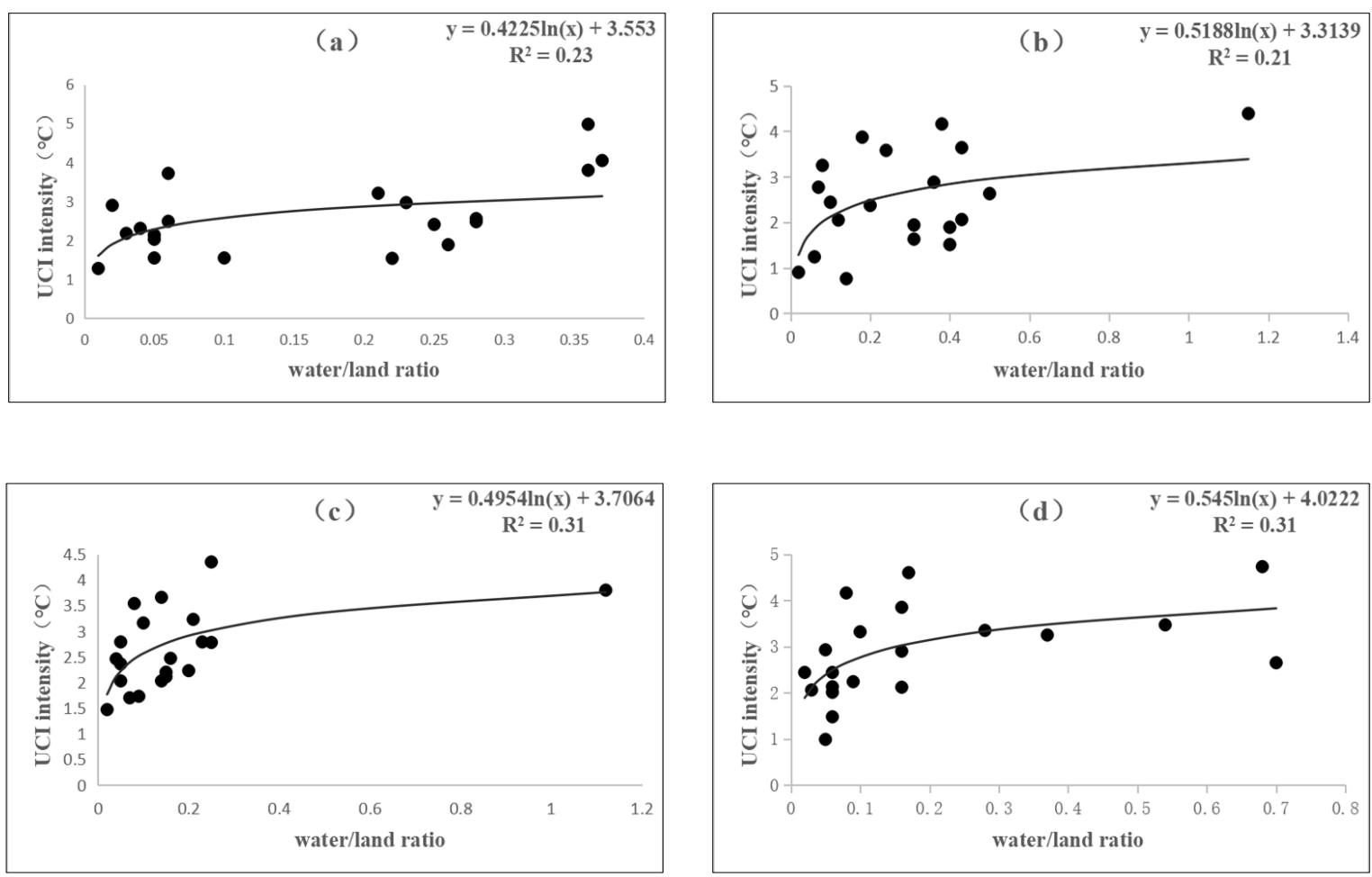

Figure 8. The TVoE of the water/land ratio of green spaces containing water bodies in each city:

(a) Beijing; (b) Tianjin; (c) Xi'an; (d) Zhengzhou.

\section{Discussion}

\subsection{Relationship between landscape indicators and UCI intensity and UCI extent}

The results of this study showed that, in cold regions in China, for green spaces without water, the higher the BGT, the lower the UCI intensity and the lesser the cooling effect. For green spaces containing water bodies, different situations were observed in the four cities due to the cooling effect of the water inside the spaces. In Beijing and Xi'an, the correlation between the BGT of the green spaces containing water bodies and their UCI intensity is extremely low, 
while Tianjin and Zhengzhou have strong negative correlations. Therefore, we believe that there is no correlation between the BGT and the UCI intensity. Studies have shown that water bodies can reduce the maximum temperature and increase the minimum temperature due to their "constant temperature effect". In the present study, it was found that the proportion of water bodies of green spaces in the four cities is weakly negatively correlated with the spaces' internal temperature and is positive correlated with the UCI intensity, which shows that the water bodies inside of the green spaces have a certain impact on the BGT and the cooling effect of the patch. Therefore, researchers should analyze green spaces with water separately in the future. Except for the green spaces without water in Beijing and the green spaces with water in Tianjin and Xi'an, the BGT of all of the green spaces in other cities is negatively correlated with the UCI extent. Therefore, the results indicate that there is no correlation between the BGT and the UCI extent for two different types of green space in cold regions of China. Most of the UCI extent of the green spaces without water in Beijing is $150 \mathrm{~m}$; we think this may be related to the relatively large width of the urban roads in Beijing. Paved roads have a lower specific heat capacity, absorb heat quickly, and dissipate heat slowly, which affect the cooling effects of green spaces. The lack of correlation between the BGT of green spaces with water and the UCI extent in Tianjin and Xi'an may be due to the influence of the water bodies inside the spaces.

The area of green spaces without water in each city is positively correlated with UCI intensity to varying degrees, which is consistent with previous research results ${ }^{[46-48]}$. There is no correlation between the area of green spaces containing water bodies and UCI intensity; however, the proportion of water body in the water-bearing green space is positively correlated 
with UCI intensity in each city. This indicates that, for the green spaces containing water bodies, the proportion of the area of the internal water body to the total area of the green space is an important factor affecting the cooling effect. Studies have shown that, by increasing the size of the water body, the cooling intensity of the water body increases and its cooling efficiency decreases ${ }^{[49-51]}$. Except for Beijing, the area of green spaces without water in each city is positively correlated with the UCI extent to varying degrees. The correlation between the area of green spaces containing water bodies in Beijing and Tianjin and the UCI extent is extremely low, while that in Xi'an and Zhengzhou is positive. This may be related to the higher BGT in Xi'an and Zhengzhou. Studies have shown that the higher the urban background temperature, the stronger the cooling effect of urban water bodies ${ }^{[52-53]}$. Therefore, in Xi'an and Zhengzhou, where the urban background temperature is relatively high, green spaces containing water bodies have a stronger cooling effect.

There is no correlation between the LSI of the selected green spaces in the four cities and UCI intensity or UCI extent, which is different from the conclusion of Yu that the LSI of green space is positively correlated with UCI intensity ${ }^{[26]}$. This may be because the four cities selected in this study all use a square road network, so the selected sample green spaces have relatively low shape complexity and are basically close to a square.

\subsection{TVoE}

In this study, we found that there is a TVoE for green spaces without water in cities in cold regions, which ranges from 0.44 ha to 0.57 ha. Therefore, it can be considered that the TVoE of green spaces without water in cold regions of China is about 0.52 ha. Additionally, this study 
found that the TVoE is related to the average BGT of the green spaces but not to the average NDVI of the green spaces, which is different from the conclusion of $\mathrm{Yu}{ }^{[33]}$ that the TVoE of green spaces is highly correlated with the NDVI and the urban background temperature. For green spaces, the higher the BGT, the lower the cooling effect. At this time, it is necessary to increase the areas of individual green spaces to improve their cooling effect. However, for the NDVI, although the green spaces in cities in cold regions of China have a large amount of vegetation, the vegetation types inside a single patch are relatively limited in diversity; therefore, since the NDVI is affected by the vegetation and environmental and atmospheric conditions, there is no correlation between the NDVI and the TVoE.

For green spaces containing water bodies, none of the four cities has a TVoE for its area. Furthermore, considering that water is an important factor affecting the cooling effect of the entire green space, we continued to study the TVoE of the water/land ratio in the green spaces. We found that the water/land ratio of the green spaces containing water bodies in the four cities is positively correlated with the UCI intensity, with TVoEs of $0.42,0.52,0.50$, and 0.55 for Beijing, Tianjin, Xi'an, and Zhengzhou, respectively.

\subsection{Guidance on urban planning and management}

Urban green space can play an important role in mitigating the UHI effect due to its cooling effect. This study confirms that green spaces containing water bodies have a stronger cooling effect than those without water bodies. In cold regions of China, as water resources are not abundant, there are few green spaces containing bodies of water. Therefore, water should be designed within green spaces. Previous studies have confirmed that the size of a green space 
is positively correlated with its cooling intensity; however, there is a TVoE- that is, when the area of green space exceeds this threshold, the cooling efficiency of green space will become lower. This study found that, in cold regions of China, there is only a TVoE for green spaces without water, and the threshold ranges from 0.44 ha to 0.57 ha. However, the average area of the selected sample green space is 3.33 ha, which is obviously bigger than the TVoE. This means that, for green spaces without water in cold regions of China, designers should try to ensure that the area is about 0.52 ha to optimize the cooling efficiency of the green space. For green spaces containing water bodies, although there is no TVoE for their area, when the ratio of the internal water area to the area of the green space is 0.5 , the cooling efficiency is the highest. Therefore, more emphasis should be placed on the area ratio of the various design elements inside the green space.

\subsection{Research limitations and future research directions}

First, this study analyzed the cooling effects of two different types of urban green space in cold regions of China. In future research, more cities and more sample green spaces can be selected, and more high-precision satellite images can be used to improve the accuracy of the research results. Secondly, every city is unique, an open and complex giant system with nonlinearity and high uncertainty. Although cities in the same climate region have roughly the same background conditions, there are still internal differences and many factors that affect the cooling effect of urban green spaces - one of which is the presence of a water body. Additionally, the external environment of the city is also an important factor. Therefore, in future research, more factors that influence the cooling effect of urban green spaces need to be included for a more comprehensive analysis. Generally speaking, an urban water body is called 
an urban blue space. For urban spaces with both a water body and green space, besides external urban factors, the location and shape of the water body inside the green space will also affect the cooling effect of the entire green space. Determining how to quantify the cooling effect more accurately and put forward guiding opinions that can further guide the planning and design of urban green spaces are also key considerations for future research.

\section{Conclusion}

This paper mainly studies the cooling effects of urban green spaces in cold regions of China. Considering that a water body inside an urban green space may affect the cooling effect of the green space, we divided urban green spaces into two types for the present research. The following findings were made: (1) Green spaces containing water bodies have a stronger cooling effect than green spaces without water; (2) For green spaces without water, the BGT is negatively correlated with the UCI intensity while its area is positively correlated with the UCI intensity to varying degrees; due to the differences in the internal climate and construction conditions of each city, the BGT and the area of this type of green space are not related to the UCI extent; (3) For green spaces containing water bodies, the cooling effect is different in different cities because of the water in green spaces and the different urban background conditions; The proportion of internal water area to the green space area is an important factor affecting the cooling effect of the entire green patch: as the water area inside the green space increases, the cooling effect of the green space increases; (4) In the cold regions of China, due to the fact that the cities in this region are basically square road networks, the shape of urban green spaces there is not complex, so there is no relationship between the complexity of urban green spaces and their cooling effects; (5) There is a TVoE for the area of green spaces without 
water in cities in cold regions of China, ranging from 0.44 ha to $0.57 \mathrm{ha}$, while there is no TVoE for the area of green areas containing water bodies. Further research on the water area inside the green spaces found that there is a $\mathrm{TVoE}$ for the water/land ratio of the green spaces containing water bodies for each of the four cities, which are $0.42,0.52,0.50$, and 0.55 for Beijing, Tianjin, Xi'an, and Zhengzhou, respectively. In general, this research provides useful information for planners and managers of cities in cold regions of China and expands the research perspective of classifying green spaces.

\section{Ethics approval and consent to participate}

Not applicable.

\section{Consent for publication}

Written informed consent for publication was obtained from all participants.

\section{Availability of data and materials}

The data that support the findings of this study available from the corresponding author upon reasonable request.

\section{Competing interests}

The authors claim that there is no conflicts of interests.

\section{Funding and Acknowledgement}

This work was financially supported by the National Natural Science Foundation of China 
(no:51678058) and Shaanxi National Science Foundation (No. 2019JM-475). And thanks for the two anonymous reviewers.

\section{Authors' contributions}

Bo Pang designed research, performed research, analyzed data, and wrote the paper. The remaining authors contributed to refining the ideas, carrying out additional analyses and finalizing this paper.

\section{Authors' information}

Bo Pang, Department of Architecture, Chang'an University, Xi'an 701165, China, 337410063@qq.com

Jingyuan Zhao, Department of Architecture, Chang'an University, Xi'an 701165, China, zjytougao@outlook.com

Jianxin Zhang, Department of Architecture, Chang'an University, Xi'an 701165, China, 534341570@qq.com

Li Yang, Department of Architecture, Chang'an University, Xi'an 701165, China, 2216376084@qq.com

\section{References}

[1] United Nations, 2018. World Urbanization Prospects 2018: Key Facts. In.

[2] Morgan Stanley,2019. The rise of China's supercities: new era of urbanization 
[3] Pollio, and A. Carol. "Urban Ecology: Science of Cities. By Richard T. T. Forman. Cambridge and New York: Cambridge University Press. $\$ 120.00$ (hardcover); $\$ 60.00$ (paper). xiv +462 p.; ill.; index. ISBN: $978-$ 1-107-00700-0 (hc); 978-0-521-18824-1 (pb). 2014." Quarterly Review of Biology 91.2(2016):212-212.

[4] Jaganmohan, Madhumitha, et al. "The Bigger, the Better? The Influence of Urban Green Space Design on Cooling Effects for Residential Areas." Journal of Environmental Quality 45.1(2016):134.

[5] Kaza, and Nikhil. "The changing urban landscape of the continental United States." Landscape and Urban Planning 110(2013):74-86.

[6] "Sustainable urban metabolism as a link between bio-physical sciences and urban planning: The BRIDGE project." Landscape \& Urban Planning 112(2013):100-117.

[7] Manoli, Gabriele, et al. "Magnitude of urban heat islands largely explained by climate and population." Nature 573.7772(2019):55-60.

[8] Voogt, J. A, and T. R. Oke . "Thermal remote sensing of urban climates." Remote Sensing of Environment 86.3(2003):370-384.

[9] Oke, T. R., et al. Urban Climates||Geographical Controls. 2017.

[10] Kalnay, E., and M. Cai. "Impact of urbanization and land-use change on climate." Nature 423.6939(2003):528-531.

[11] Sun, Y., Zhang, X., Zwiers, F. et al. Rapid increase in the risk of extreme summer heat in Eastern China. Nature Clim Change 4, 1082-1085 (2014).

[12] Santarnouris, Mattheos, and D. Kolokotsa. "On the impact of urban overheating and extreme climatic 
conditions on housing, energy, comfort and environmental quality of vulnerable population in Europe." Energy \& Buildings 98. jul. (2015):125-133.

[13] Akbari, Hashem, and D. Kolokotsa . "Three decades of urban heat islands and mitigation technologies research." Energy \& Buildings 133. DEC. (2016):834-842.

[14] Wong, Pui Yun, et al. "The impact of environmental and human factors on urban heat and microclimate variability." Building and Environment 95(2016):199-208.

[15] Zhou, Decheng, et al. "Remote sensing of the urban heat island effect in a highly populated urban agglomeration area in East China." ence of the Total Environment s 628-629(2018):415-429.

[16] Galina, et al. "Effect of VOC Emissions from Vegetation on Air Quality in Berlin during a Heatwave." Environ.sci.technol (2017).

[17] OKE, and TR. "THE MICROMETEOROLOGY OF THE URBAN FOREST." Phil Trans Roy Soc London B (1989).

[18] Fan, C., S. W. Myint, and B. Zheng. "Measuring the spatial arrangement of urban vegetation and its impacts on seasonal surface temperatures." Progress in Physical Geography 39.2(2015):199-219.

[19] Kong, Fanhua, et al. "A satellite image-based analysis of factors contributing to the green-space cool island intensity on a city scale." Urban Forestry \& Urban Greening 13.4(2014):846-853.

[20] Middel, et al. "Remote sensing of the surface urban heat island and land architecture in Phoenix, Arizona: Combined effects of land composition and configuration and cadastral-demographic-economic factors." Remote Sensing of Environment: An Interdiplinary Journal 174(2016):233-243. 
[21] Asgarian, Ali, B. J. Amiri , and Y. Sakieh . "Assessing the effect of green cover spatial patterns on urban land surface temperature using landscape metrics approach." Urban Ecosystems 18.1(2015):209-222.

[22] Ren, Yin, et al. "Quantifying the influences of various ecological factors on land surface temperature of urban forests." Environmental Pollution 216.216(2016):519-529.

[23] Taleghani, Mohammad. "Outdoor thermal comfort by different heat mitigation strategies- A review." Renewable \& Sustainable Energy Reviews 81(2017):2011-2018.

[24] Feyisa, G. L., K. Dons, and H. Meilby. "Efficiency of parks in mitigating urban heat island effect: An example from Addis Ababa." Landscape \& Urban Planning 123.2(2014):87-95.

[25] Teresa Z, et al. "Using green infrastructure for urban climate-proofing: An evaluation of heat mitigation measures at the micro-scale." Urban Forestry \& Urban Greening 20(2016):305-316.

[26] Yu, Zhaowu, et al. "How can urban green spaces be planned for climate adaptation in subtropical cities?

" Ecological Indicators 82. nov. (2017):152-162.

[27] Liang, B, and Q. Weng. "Assessing Urban Environmental Quality Change of Indianapolis, United States, by the Remote Sensing and GIS Integration." IEEE Journal of Selected Topics in Applied Earth Observations \& Remote Sensing 4.1(2011):43-55.

[28] Mikami, T., Sekita, Y., 2009. Quantitative evaluation of cool island effects in urban green parks. In: The seventh International Conference on Urban Climate. Yokohama, Japan.

[29] Jaganmohan, Madhumitha, et al. "The Bigger, the Better? The Influence of Urban Green Space Design on Cooling Effects for Residential Areas." Journal of Environmental Quality 45.1(2016):134. 
[30] Yu, Zhaowu, et al. "Strong contributions of local background climate to the cooling effect of urban green vegetation." entific Reports 8.1(2018):6798.

[31] Le, Minh Tuan, T. A. T. Cao, and N. A. Q. Tran. "The role of green space in the urbanization of Hanoi city." E3S Web of Conferences 97(2019):01013.

[32] Yang, Gaoyuan, et al. "How can urban blue-green space be planned for climate adaption in high-latitude cities? A seasonal perspective." Sustainable Cities and Society 53(2020):101932.

[33] Fan, Huiying, et al. "How to cool hot-humid (Asian) cities with urban trees? An optimal landscape size perspective." Agricultural and Forest Meteorology 265(2019):338-348.

[34] Peng, Jian, et al. "How to effectively mitigate urban heat island effect? A perspective of waterbody patch size threshold." Landscape and Urban Planning 202(2020):103873.

[35] Wu, Jiansheng, et al. "Seasonal variations and main influencing factors of the water cooling islands effect in Shenzhen." Ecological Indicators 117(2020).

[36] Yu, Ke, et al. "Quantitative analysis of the interannual variation in the seasonal water cooling island (WCI) effect for urban areas." ence of The Total Environment 727.

[37] Hongyu, Du, et al. "Research on the cooling island effects of water body: A case study of Shanghai, China." Ecological Indicators 67. aug. (2016):31-38.

[38] Wu, Zhifeng, and Y. Ren. "A bibliometric review of past trends and future prospects in urban heat island research from 1990 to 2017." Environmental Reviews (2018).

[39] Yu, Zhao Wu, Q. H. Guo, and R. H. Sun. "Impacts of urban cooling effect based on landscape scale: A 
review." Ying Yong Sheng Tai Xue Bao 26.2(2015):636-642.

[40] Yu, Zhaowu, et al. "Critical review on the cooling effect of urban blue-green space: A threshold-size perspective." Urban Forestry \& Urban Greening 49(2020):126630.

[41] Estoque, Ronald C., Y. Murayama, and S. W. Myint. "Effects of landscape composition and pattern on land surface temperature: An urban heat island study in the megacities of Southeast Asia." Science of the Total Environment 577.JAN.15(2017):349-359.

[42] Gunawardena, K. R., M. J. Wells, and T. Kershaw. "Utilising green and bluespace to mitigate urban heat island intensity." ence of The Total Environment s 584-585(2017):1040-1055.

[43] Kuang, Wenhui, et al. "What are hot and what are not in an urban landscape: quantifying and explaining the land surface temperature pattern in Beijing, China." Landscape Ecology 30.2(2015):357-373.

[44] Santamouris, M. "Cooling the cities - A review of reflective and green roof mitigation technologies to fight heat island and improve comfort in urban environments." Solar Energy 103.may(2014):682-703.

[45] ISO 7243-2017

[46] Bowler, Diana E., et al. "Urban greening to cool towns and cities: A systematic review of the empirical evidence." Landscape \& Urban Planning 97.3(2010):147-155.

[47] Chang, Chi Ru, M. H. Li, and S. D. Chang. "A preliminary study on the cool-island intensity of Taipei city parks." Landscape and Urban Planning 80.4(2007):386-395.

[48] Manoli, Gabriele, et al. "Magnitude of urban heat islands largely explained by climate and population." Nature 573.7772(2019):55-60. 
[49] Lin, Wenqi, et al. "Calculating cooling extents of green parks using remote sensing: Method and test." Landscape \& Urban Planning 134(2015):66-75.

[50] Sun, Ranhao, and L. Chen. "How can urban water bodies be designed for climate adaptation?." Landscape \& Urban Planning 105.1-2(2012):27-33.

[51] Theeuwes, N. E., Solcerová, A., and G. J. Steeneveld. "Modeling the influence of open water surfaces on the summertime temperature and thermal comfort in the city." Journal of Geophysical Research: Atmospheres 118.16(2013).

[52] Hathway, E. A., and S. Sharpies. "The interaction of rivers and urban form in mitigating the Urban Heat Island effect: A UK case study." Building \& Environment 58. DEC. (2012):14-22.

[53] Murakawa, Saburo, et al. "Study of the effects of a river on the thermal environment in an urban area." Energy \& Buildings 16.s 3-4(1991):993-1001. 


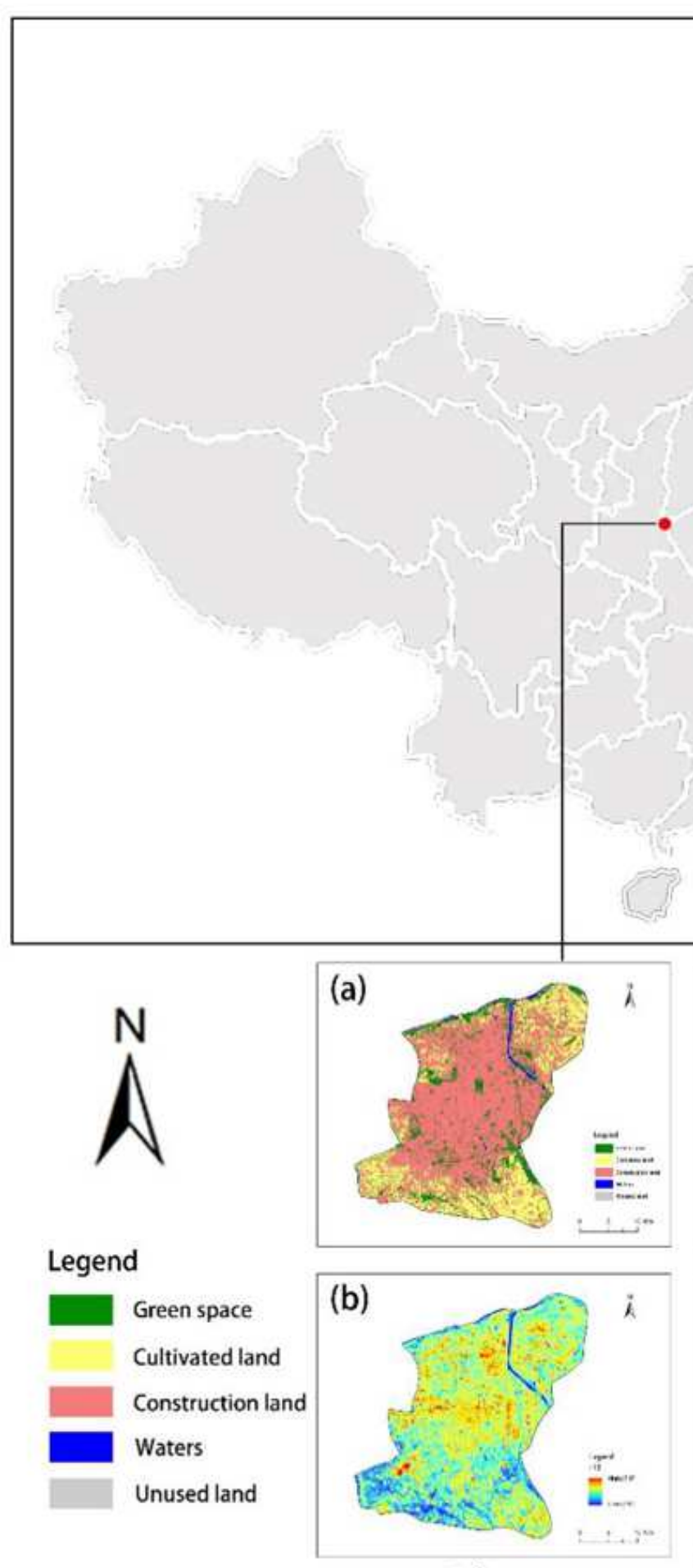

Xi'an
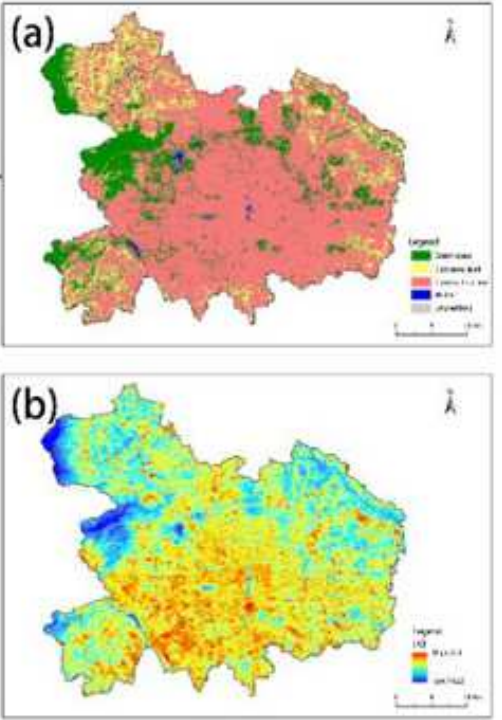

Beijing

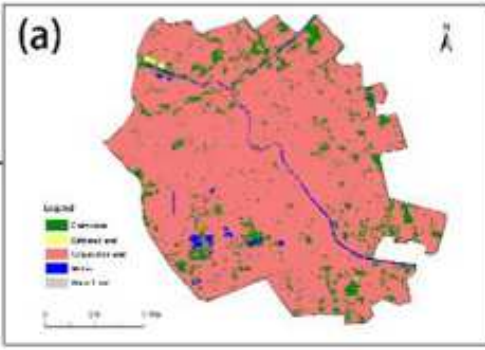

(a)
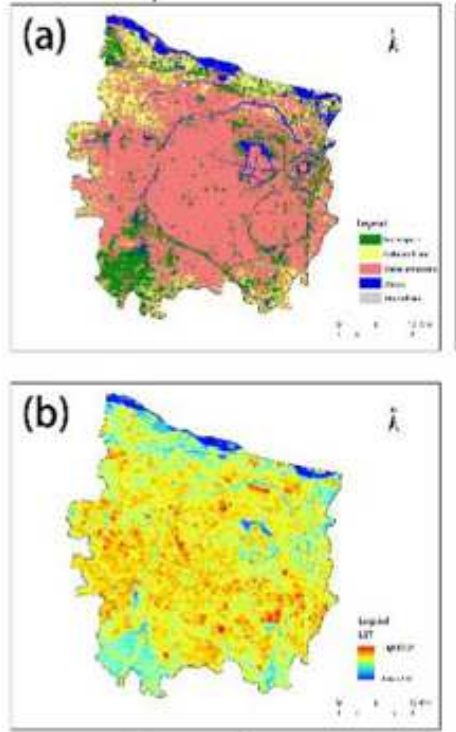

Zhengzhou

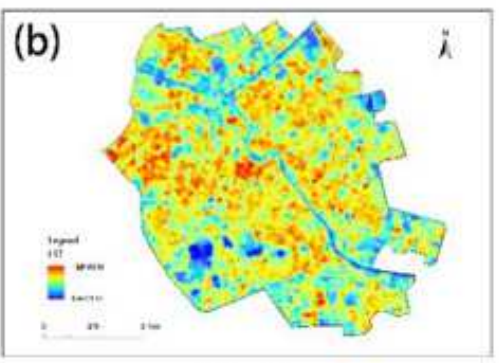

Tianjin

\section{Figure 1}

The basic geographic information of the selected cities: (a) Land cover classification; (b) Land surface temperature. Note: The designations employed and the presentation of the material on this map do not imply the expression of any opinion whatsoever on the part of Research Square concerning the legal 
status of any country, territory, city or area or of its authorities, or concerning the delimitation of its frontiers or boundaries. This map has been provided by the authors.

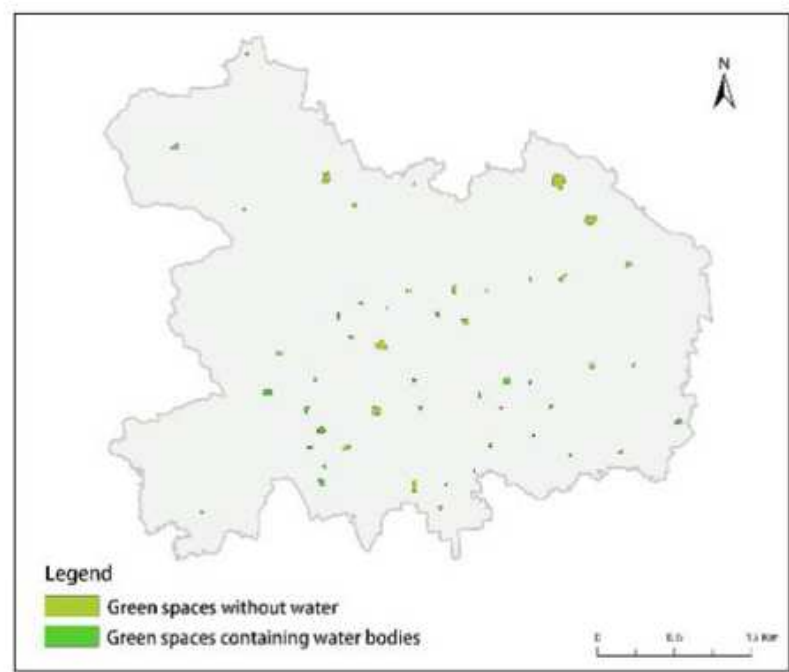

(a)

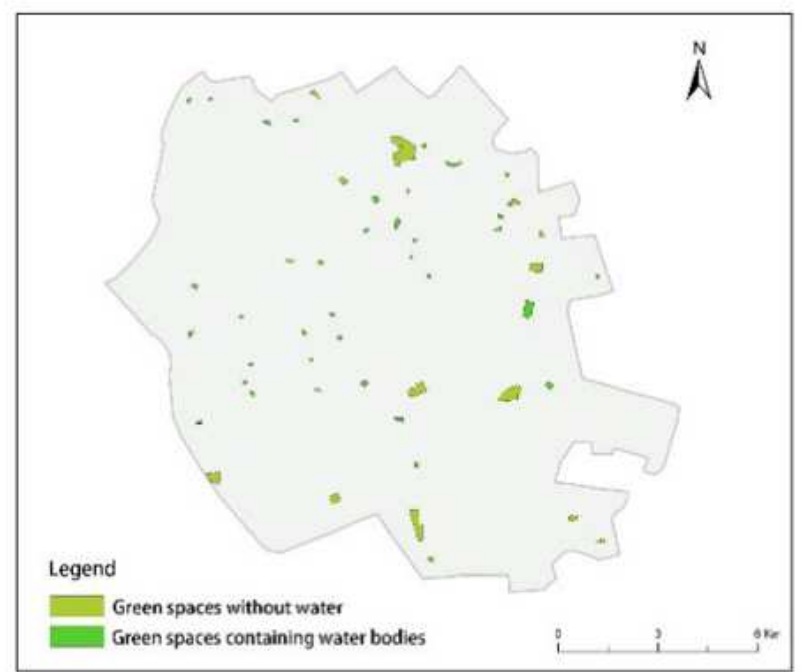

(b)

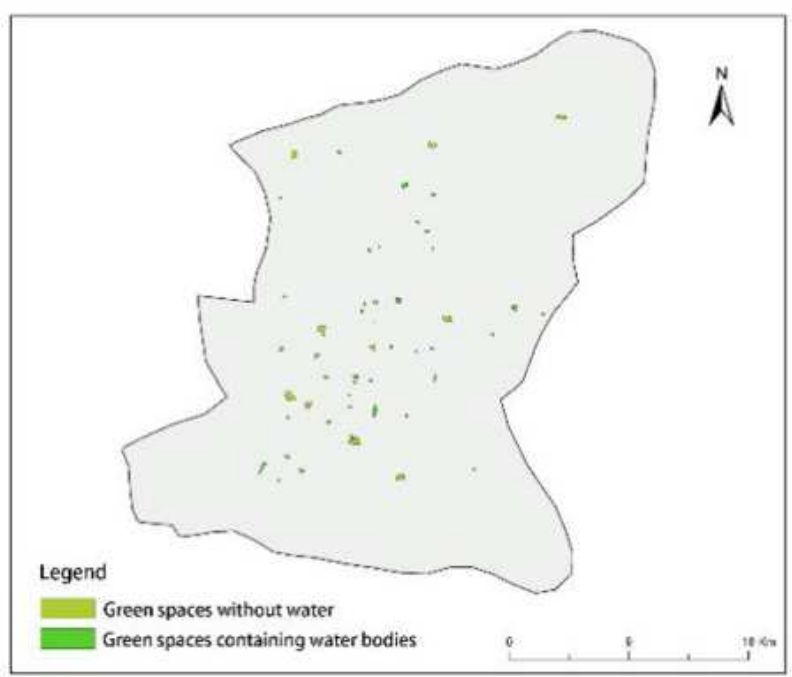

(c)

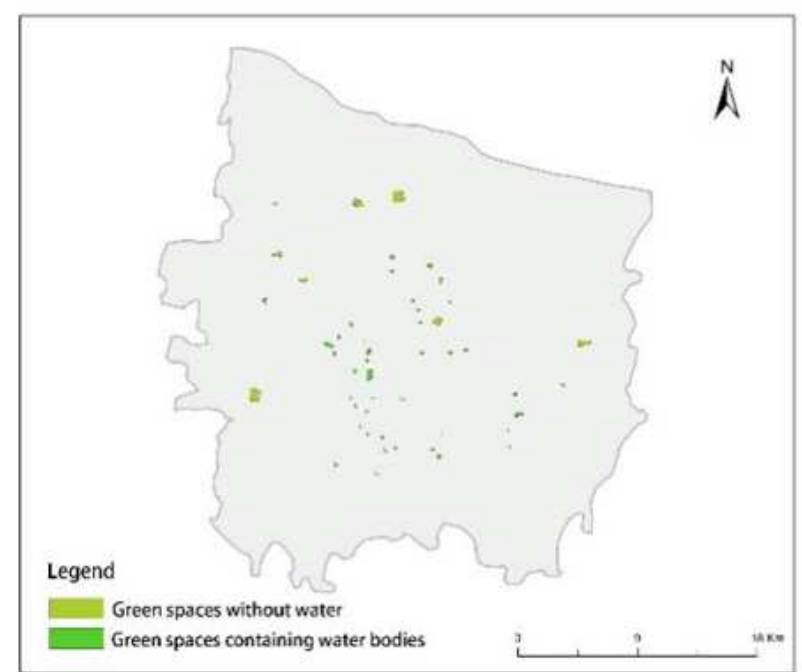

(d)

\section{Figure 2}

Results of urban green space selection: (a) Beijing; (b) Tianjin; (c) Xi'an; (d) Zhengzhou. Note: The designations employed and the presentation of the material on this map do not imply the expression of any opinion whatsoever on the part of Research Square concerning the legal status of any country, territory, city or area or of its authorities, or concerning the delimitation of its frontiers or boundaries. This map has been provided by the authors. 

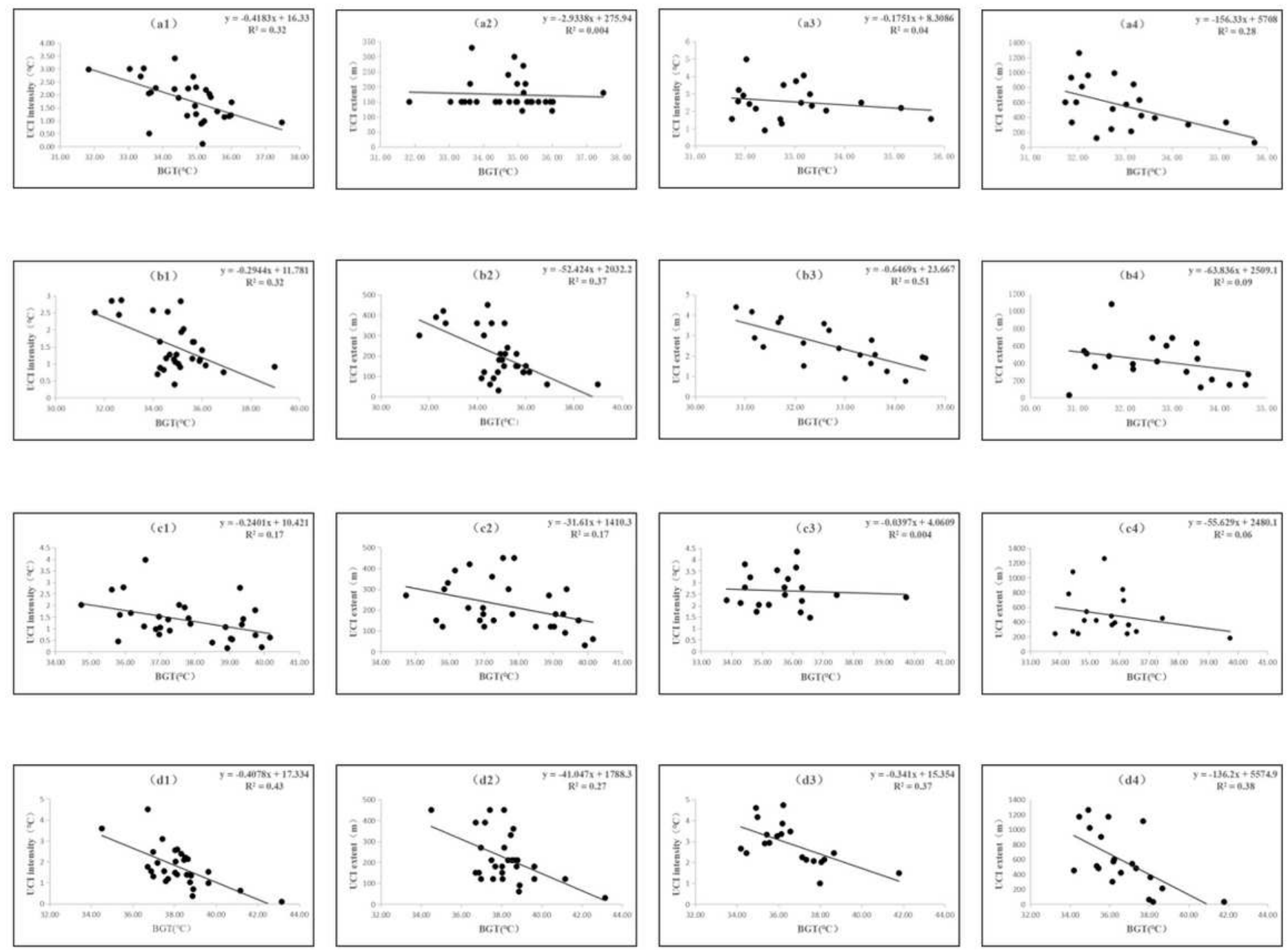

Figure 3

Correlation analysis between background temperature and $\mathrm{UCl}$ intensity and $\mathrm{UCI}$ range for two different

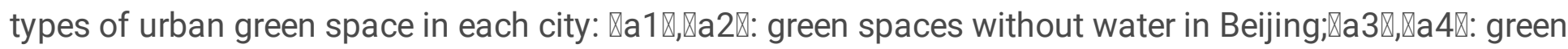

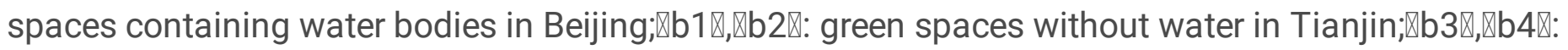

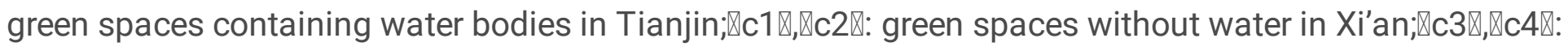

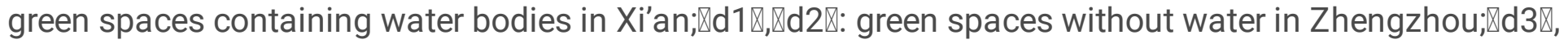
$\llbracket \mathrm{d} 4 \rrbracket$ : green spaces containing water bodies in Zhengzhou. 

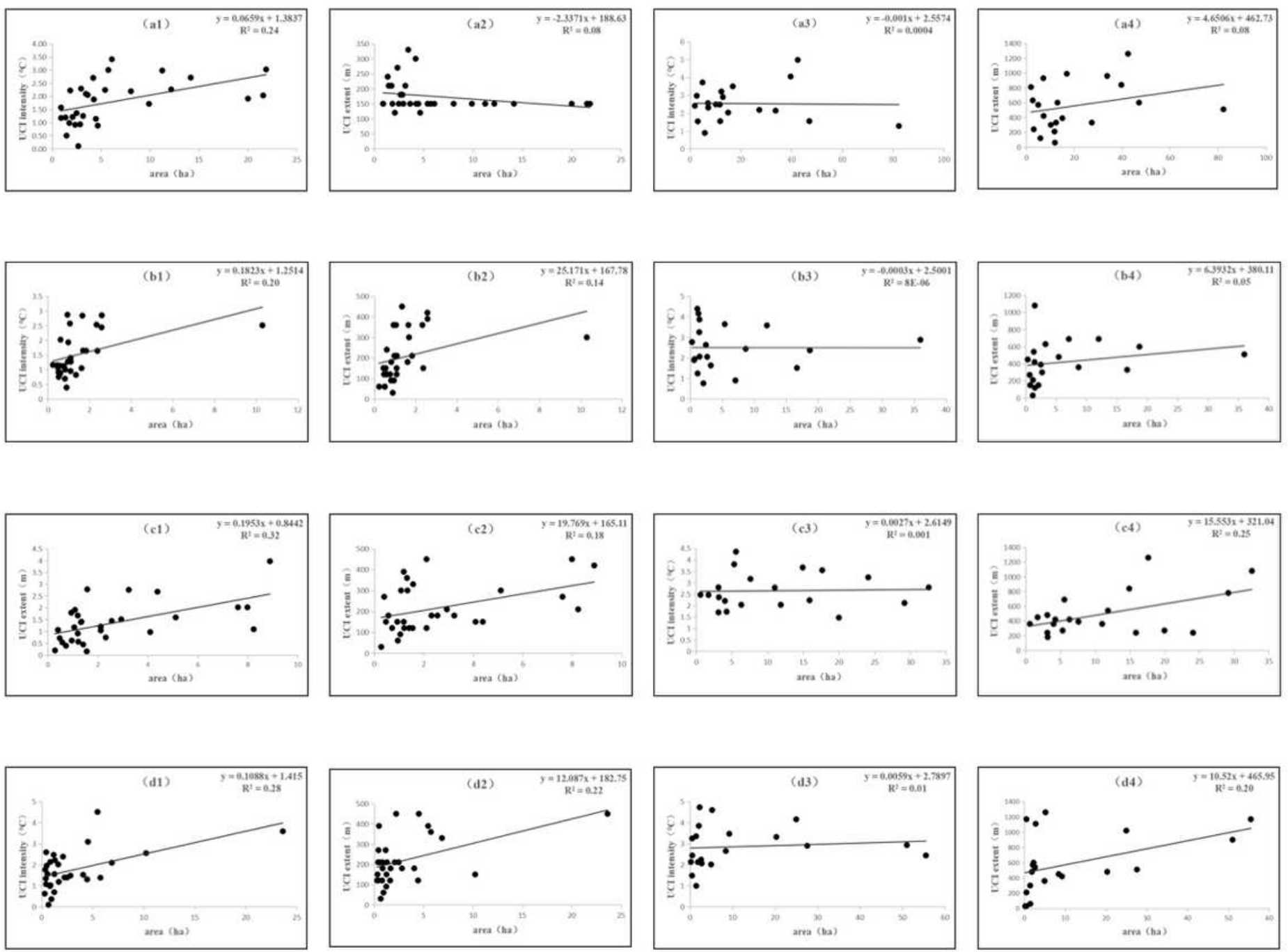

\section{Figure 4}

Correlation analysis between the area of two different types of urban green space in each city with UCl

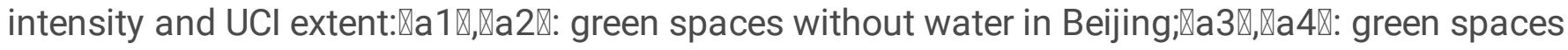

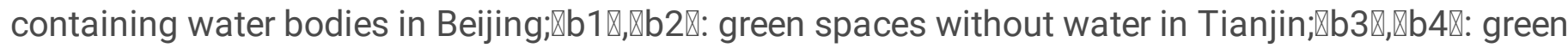

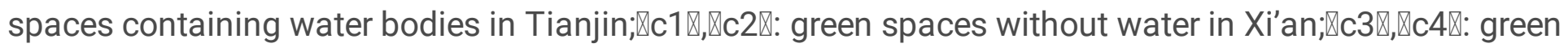

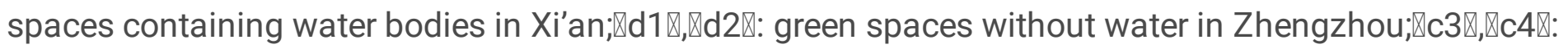
green spaces containing water bodies in Zhengzhou. 

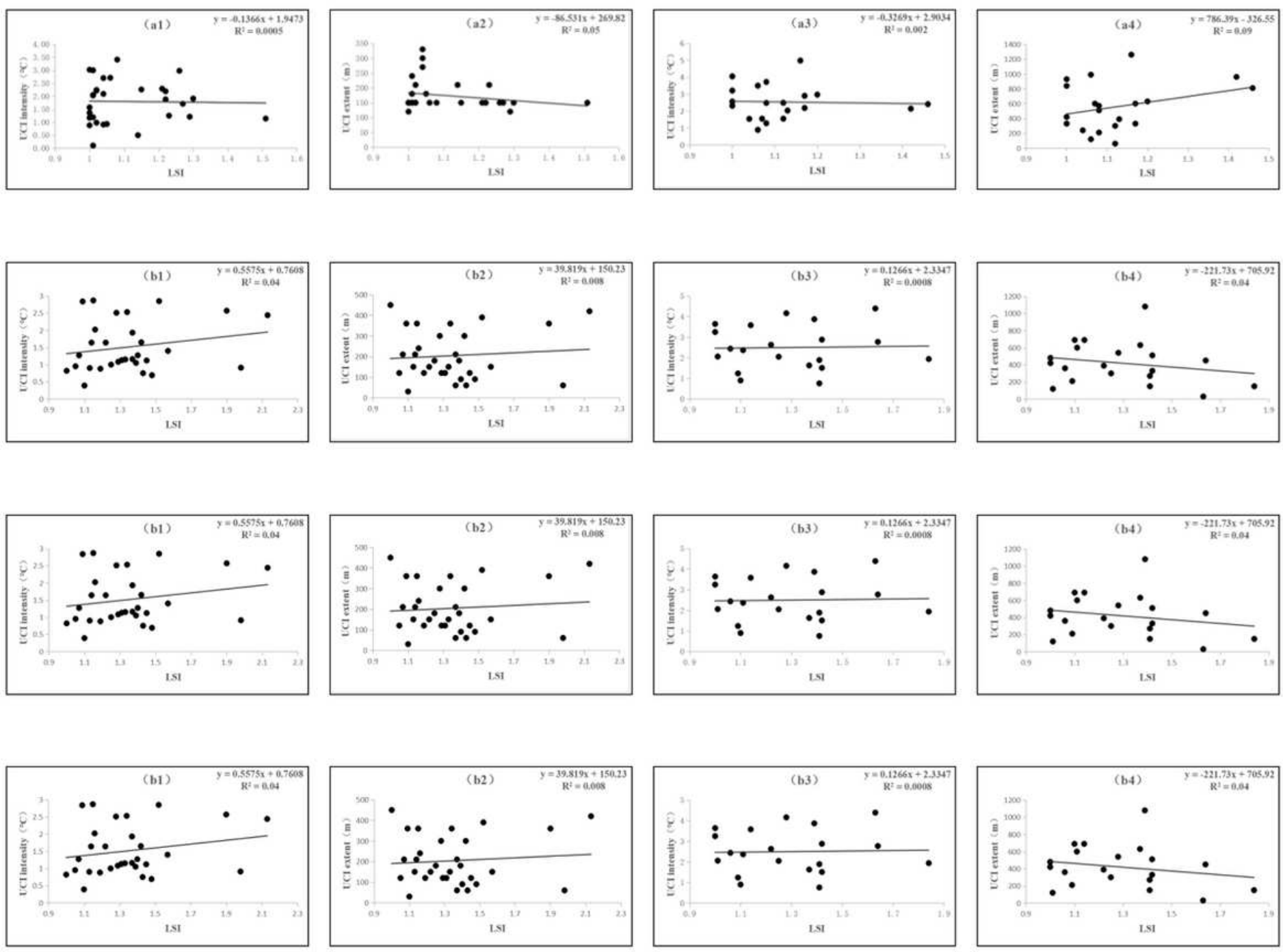

\section{Figure 5}

Correlation analysis between the landscape sub-dimension index, $\mathrm{UCl}$ intensity, and $\mathrm{UCl}$ extent of two

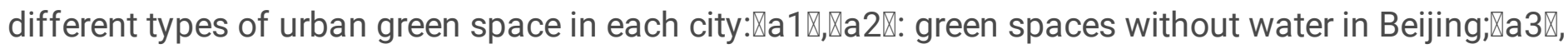

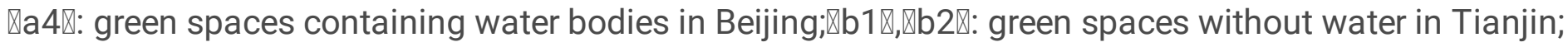

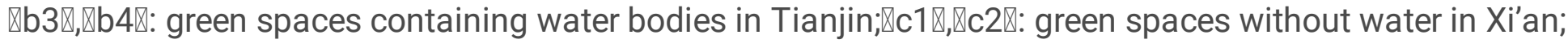

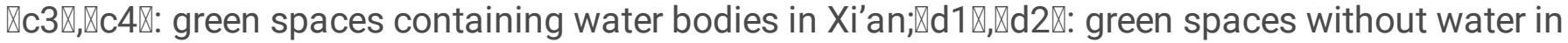

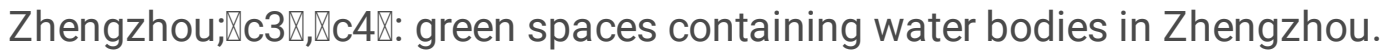



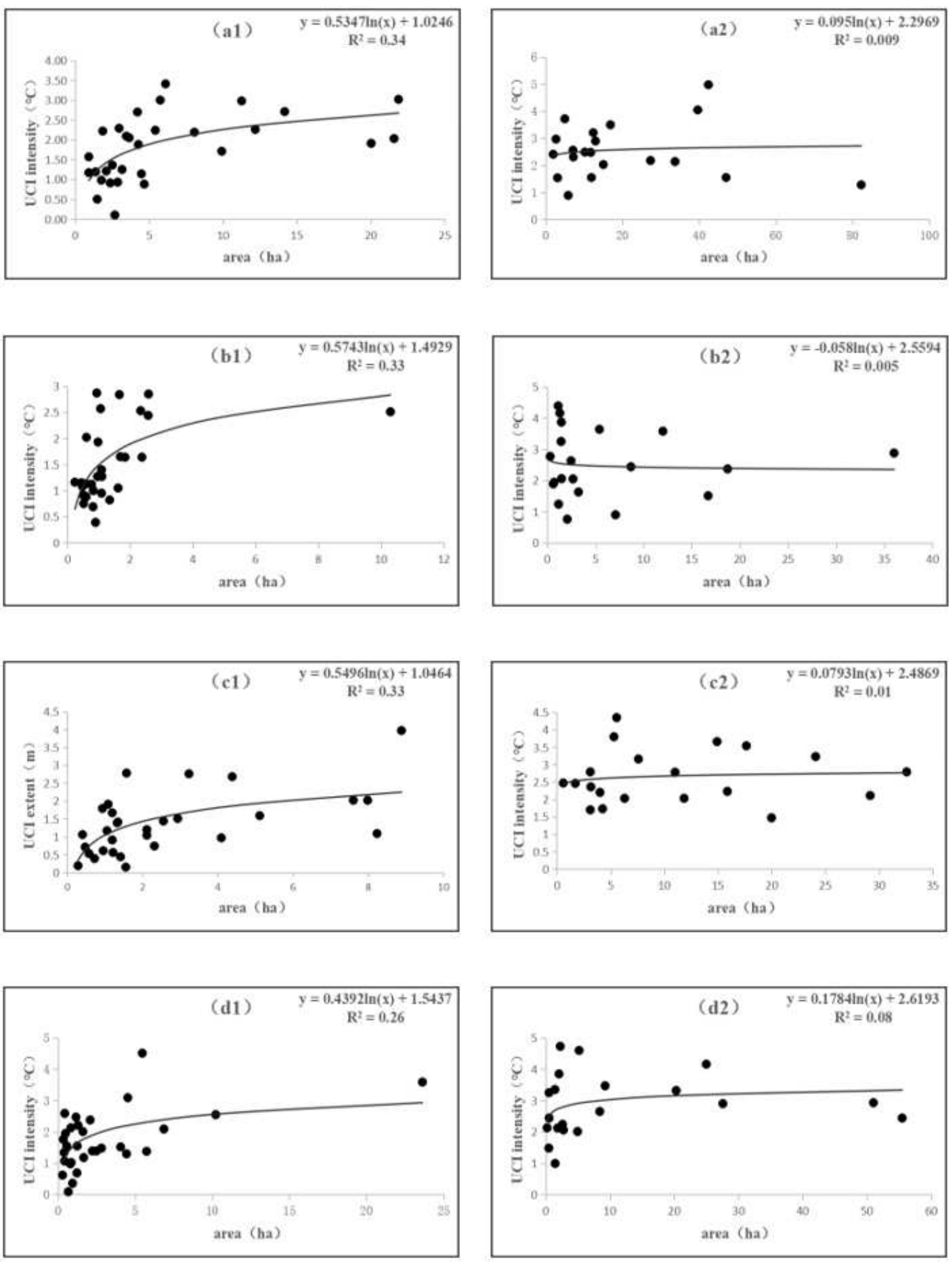

Figure 6

TVoEs of two different types of urban green space in each city: (a1): green spaces without water in Beijing; (a2): green spaces containing water bodies in Beijing; (b1): green spaces without water in Tianjin; (b2): green spaces containing water bodies in Tianjin; (c1): green spaces without water in Xi'an; (c2): green spaces containing water bodies in Xi'an; (d1): green spaces without water in Zhengzhou; (d2): green spaces containing water bodies in Zhengzhou. 

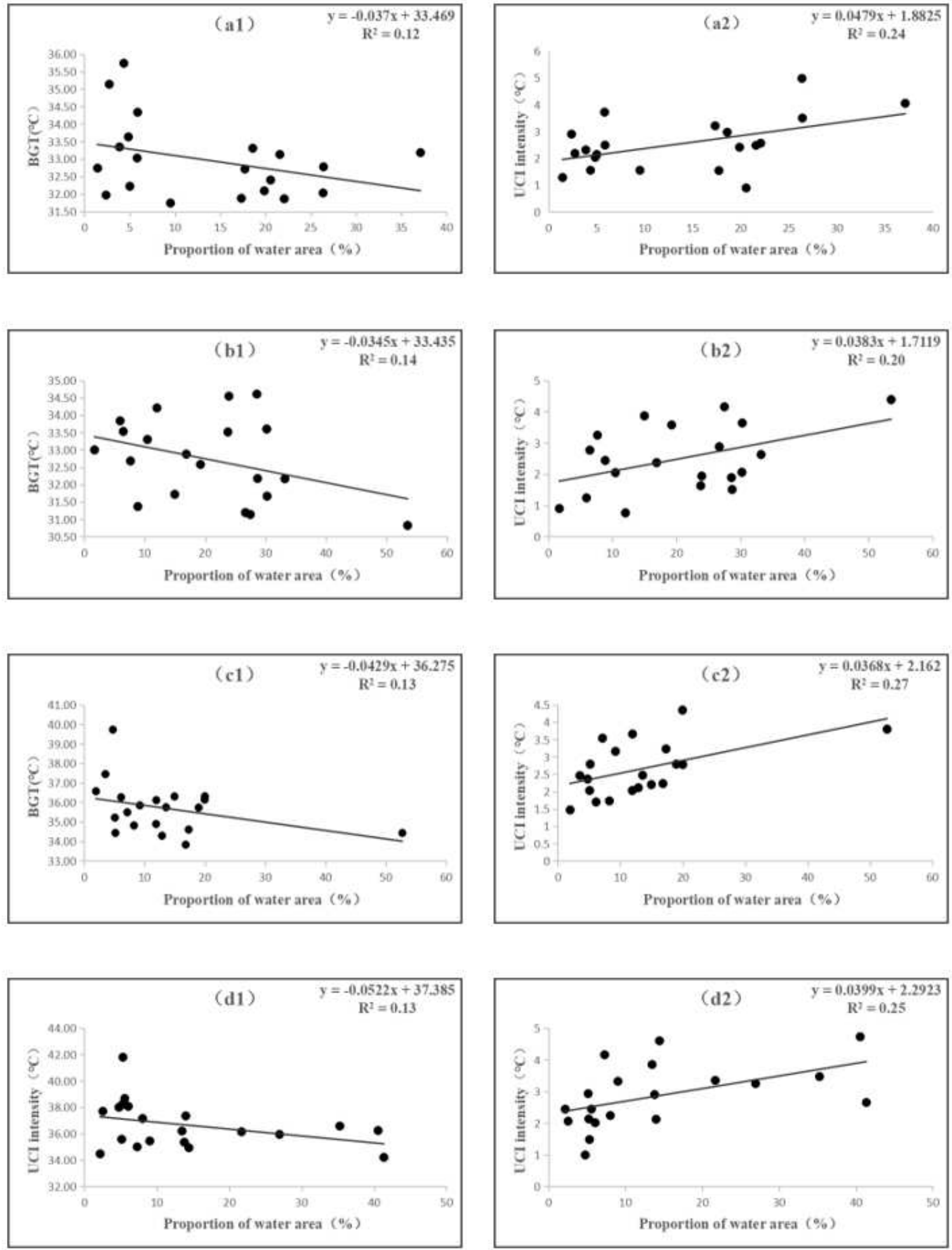

Figure 7

Correlation analysis of the proportion of water body area and $\mathrm{UCl}$ intensity and the internal temperature of green spaces with water in each city: (a) Beijing; (b) Tianjin; (c) Xi'an; (d) Zhengzhou. 

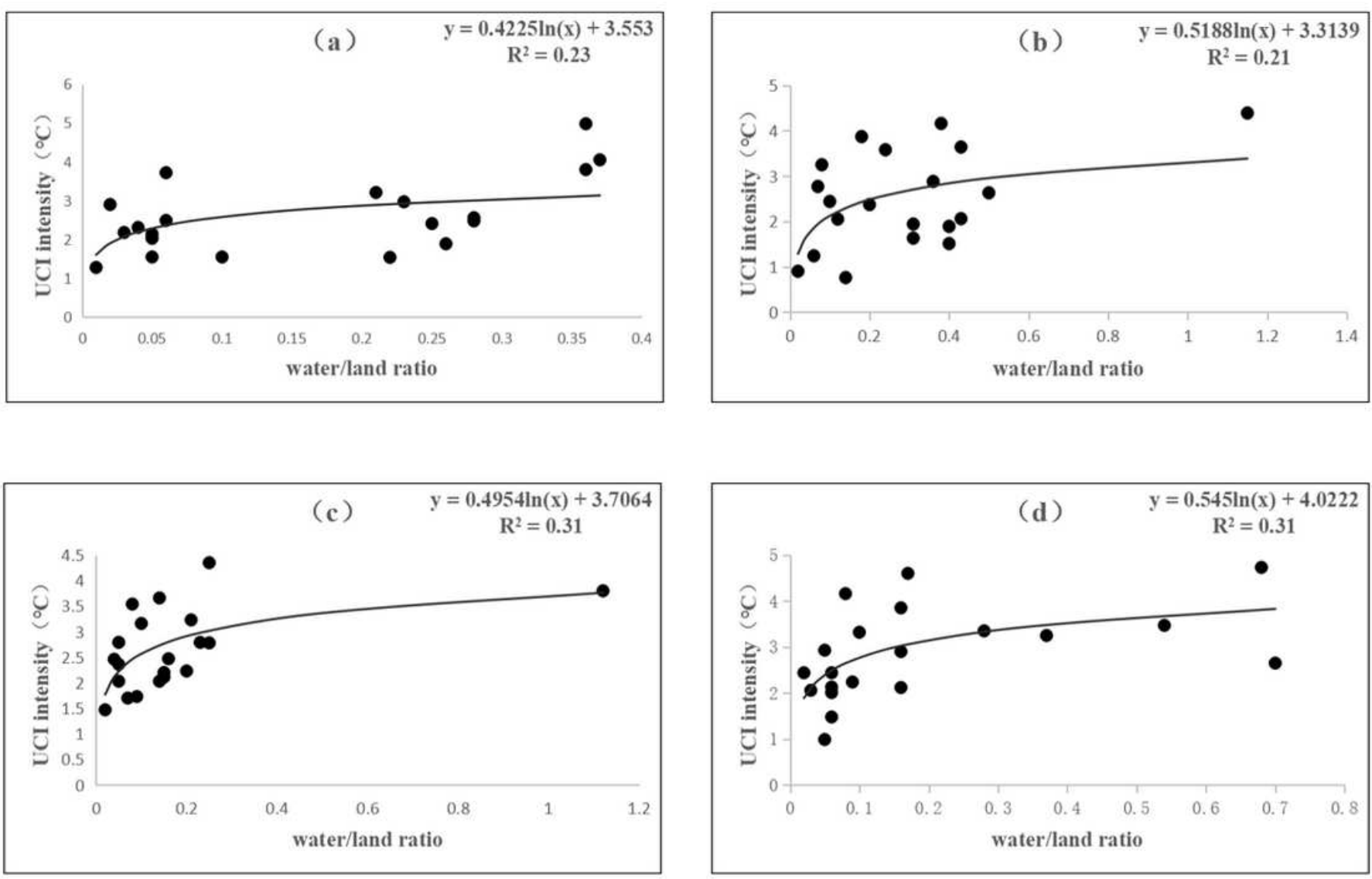

\section{Figure 8}

The TVoE of the water/land ratio of green spaces containing water bodies in each city: (a) Beijing; (b) Tianjin; (c) Xi'an; (d) Zhengzhou.

\section{Supplementary Files}

This is a list of supplementary files associated with this preprint. Click to download.

- hightlight.docx 